\title{
Technology challenges of stealth Unmanned Combat Aerial Vehicles
}

\author{
E. Sepulveda ${ }^{1}$, H. Smith \\ School of Aerospace, Transport and Manufacturing \\ Cranfield University \\ Cranfield \\ Beds, UK
}

\begin{abstract}
The ever changing battlefield environment, as well as the emergence of global command and control architectures currently used by armed forces around the globe, requires the use of robust and adaptive technologies integrated into a reliable platform. Unmanned Combat Aerial Vehicles (UCAVs) aim to integrate such advanced technologies while also increasing the tactical capabilities of combat aircraft. This paper provides a summary of the technical and operational design challenges specific to UCAVs, focusing on highperformance, and stealth designs. After a brief historical overview, the main technology demonstrator programmes currently under development are presented. The key technologies affecting UCAV design are identified and discussed. Finally, this paper briefly presents the main issues related to airworthiness, navigation, and ethical concerns behind UAV/UCAV operations.
\end{abstract}

\section{KEYWORDS}

UCAV, UAV, Stealth, MDO, Composites, Airworthiness, Drone strike.

\section{NOMENCLATURE}

\begin{tabular}{ll} 
ADS-B & Automatic Dependent Surveillance-Broadcast \\
AFSS & active frequency selective surfaces \\
AMT & all-moving tip \\
AoA & angle-of-attack \\
ASTRAEA & Autonomous Systems Technology Related Airborne Evaluation \& Assessment \\
ATD & advanced technology demonstrator \\
ATR & automatic target recognition \\
AVT & Applied Vehicle Technology \\
BWB & blended wing body \\
CAAC & Civil Aviation Administration of China \\
CCTV & closed-circuit television \\
CFD & computational fluid dynamics \\
COA & Certificate of Authorization \\
CST & class shape transform \\
C3 & command, control and communication \\
DARPA & Defense Advanced Research Projects Agency (USA) \\
DEAD & destruction of enemy air defences \\
DES & detached eddy simulations \\
DLR & Deutsches Zentrum für Luft- und Raumfahrt (Germany) \\
DOD & Department of Defense (USA) \\
DRDO & Defense Research and Development Organization (India) \\
DRFM & digital radio frequency memory \\
EASA & European Aviation Safety Agency \\
EO & electro-optical \\
FAA & Federal Aviation Administration (USA) \\
FEA/M & finite element analysis/method \\
HALE & high-altitude long-endurance \\
IR & infrared \\
& \\
\hline
\end{tabular}

\footnotetext{
${ }^{1}$ Corresponding author. E-mail: e.sepulveda@cranfield.ac.uk
} 


\begin{tabular}{|c|c|}
\hline IRST & Infrared Search and Track \\
\hline ISR & Intelligence Surveillance and Reconnaissance \\
\hline JARUS & Joint Authorities for Rulemaking on Unmanned Systems \\
\hline J-UCAS & Joint Unmanned Combat Air System \\
\hline LDV & laser doppler velocimetry \\
\hline LES & large eddy simulations \\
\hline LIDAR & light detection and ranging \\
\hline LSP & lightning strike protection \\
\hline $\mathrm{LtCdr}$ & Lieutenant Commander \\
\hline MALE & medium-altitude long-endurance \\
\hline MANPADS & man portable air defence systems \\
\hline MDAO & multidisciplinary design analysis and optimisation \\
\hline MDO & multidisciplinary design optimisation \\
\hline NASA & National Aeronautics and Space Administration (USA) \\
\hline NATO & North Atlantic Treaty Organisation \\
\hline NIRATAM & NATO Infrared Air Target Model \\
\hline NRO & National Reconnaissance Office (USA) \\
\hline ONERA & Office National d'Etudes et de Recherches Aérospatiales (France) \\
\hline ONR & Office of Naval Research (USA) \\
\hline PACT & pilot authorisation and control of tasks \\
\hline PIV & particle image velocimetry \\
\hline PSP & pressure sensitive paint \\
\hline RAM & radar absorbent material \\
\hline RANS & Reynolds-averaged Navier-Stokes \\
\hline RAP & radar absorbent paint \\
\hline RAS & radar absorbent structures \\
\hline RCS & radar cross section \\
\hline RDTE & research, development, testing and evaluation \\
\hline RSM & response surface method \\
\hline RTO & NATO Research and Technology Organisation \\
\hline R\&D & research and development \\
\hline SAA & sense and avoid \\
\hline SAMS & surface-to-air missile systems \\
\hline SEAD & suppression of enemy air defences \\
\hline SQP & sequential quadratic programming \\
\hline STANAG & NATO Standardization Agreement \\
\hline TCAS & traffic collision avoidance system \\
\hline UAS & unmanned aerial system \\
\hline UAV & unmanned aerial vehicle \\
\hline UCAS-D & Unmanned Combat Air System - Demonstrator \\
\hline UCAV & unmanned combat aerial vehicle \\
\hline UCLASS & Unmanned Carrier-Launched Airborne Surveillance and Strike \\
\hline USAF & United States Air Force \\
\hline UTM & UAS traffic management \\
\hline VLM & vortex lattice method \\
\hline WWI & First World War \\
\hline WWII & Second World War \\
\hline
\end{tabular}

\subsection{INTRODUCTION}

Before arming MQ-1 Predator UAVs with Hellfire laser-guided missiles in 2001, UAVs were mainly used for intelligence, surveillance and reconnaissance (ISR) missions operating at high altitudes and low speeds in, mainly, permissive environments. Even so, unmanned aircraft were significantly more vulnerable to enemy defences, mechanical failures, and adverse weather conditions than their manned counterparts, virtually eliminating every cost and operational advantage related to unmanned operations ${ }^{(1)}$. UCAV development plans have emerged as a configuration that integrates advanced technologies with increased survivability and tactical operational capabilities in dynamic and highly contested environments, while exploiting the reduced life cycle, acquisition, and operating costs ${ }^{(2)}$. 
This paper is organised in the following manner: Section 2 provides a brief historical background of UAVs in military operations. The main Advanced Technology Demonstrator programmes currently under development are identified in Section 3. Section 4 explains the main technological challenges for UCAV designs, the dominating design constraints and their impact on other aspects of the configuration. Section 5 briefly comments on the main airworthiness, airspace integration, and navigation issues. Finally, Section 6 mentions the most relevant ethical concerns behind UAV/UCAV operations.

\subsection{HISTORICAL BACKGROUND}

The potential of unmanned aircraft in military operations was identified before the First World War, with projects like Sperry's Aerial Torpedo and the Kettering Bug being developed as early as 1913. Similarly, during WWII, the TDR-1 assault drone was developed by the US Navy and successfully used against strategic Japanese facilities in 1944. With the end of WWII and the beginning of the Cold War, American defence authorities recognized that the need to obtain reliable intelligence without the risk associated to human aircraft operators was of extreme importance. Several secret organisations within the American government such as the National Reconnaissance Office (NRO), engaged in the development of 'black' projects from which multiple reconnaissance UAVs such as the Lightning Bug resulted, serving vital roles in ISR, and electronic and psychological warfare over territories like China, North Korea and Vietnam as early as $1962^{(3)}$. The most noticeable examples of secretive high-performance aircraft are the SR-71 Blackbird, and the D-21 supersonic reconnaissance drone; both configurations operated at speeds over Mach 3 and altitudes ranging from 80,000 to 90,000 feet $^{(4)}$. Similarly, during the 1970 s and 1980s, agencies such as the Defense Advanced Research Projects Agency (DARPA), in conjunction with the private sector and international partners, developed medium/highaltitude-long-endurance (M/HALE) platforms to replace manned reconnaissance aircraft like the U-2. These efforts resulted in modern UAVs such as Predator and Global Hawk ${ }^{(5)}$.

Subsequent armed conflicts proved the value of using UAVs in intelligence roles; US Navy LtCdr. Dixon concludes on UAV employment over Kosovo: 'The primary military role of UAVs is real time data... [real time surveillance video] may significantly help the operational commander.' and to 'Aggressively continue UAV research and development. ${ }^{(6, \text { pp. } 12,14)}$

Partially based on this success, the US Office of Naval Research (ONR) Strike Technology Division conceived an ambitious and futuristic vision for fully autonomous aerial vehicles in the battlespace, from low-speed highaltitude surveillance platforms to high-performance strike and air combat aircraft; these requirements were considered unrealistic but ' $a$ worthwhile challenge and a useful direction in which to point R\&D efforts. ${ }^{\text {, }}$, p.8)

UAVs transitioned from surveillance to attack roles in 2001, when a MQ-1 Predator UAV, and later its larger variant the MQ-9 Reaper, armed with Hellfire laser-guided missiles fired against targets over Afghanistan and Kuwait $^{(8)}$. The number of 'drone strikes' has continued to increase ever since; The Bureau of Investigative Journalism reports more than 400 US Predator/Reaper strikes over Pakistan from June 2004 to September $2015^{(9)}$. Today, it is estimated that more than 70 countries possess UAVs for civil and military applications, while more than 50 countries are currently designing and developing all types of UAVs ${ }^{(10)}$, with an expected increase in global expenses for RDTE from $\$ 6.6 \mathrm{~B}$ in 2013 to $\$ 11.4 \mathrm{Bn}$ in $2022^{(11)}$.

\subsection{ADVANCED TECHNOLOGY DEMONSTRATOR PROGRAMMES}

By eliminating the immediate risk to human operators, UAVs are well suited for 'dull, dirty, dangerous and deep' missions; combined with advanced technologies, future UCAV platforms will be able to operate in highly contested airspace in pre-emptive and reactive roles such as suppression and destruction of enemy air defences (S/DEAD), penetrating surveillance, and strike of high-value targets ${ }^{(12)}$. These 'first day operations' require stealthy and agile configurations, which naturally take the form of highly blended flying-wing type designs. Therefore, this paper will deal with high-speed, high-performance, stealthy vehicles, while MALE/HALE configurations, even as they continue to be used as weapon-delivery systems today and in foreseeable future conflicts, are out of the scope of the paper.

\subsection{US Navy UCLASS}

In 1999 the US DOD began investigating a new type of unmanned vehicle that could operate in combat missions while maintaining the low-cost benefits of UAVs. Initial research was undertaken by the US Air Force (USAF), DARPA, and Boeing with the X-45A UCAV demonstrator programme. It integrated several incremental development spirals culminating in the larger and more capable X-45C, with estimated deliveries by 
$2011^{(13)}$. Shortly after, the US Navy and Northrop Grumman began developing a sea-based UCAV demonstrator designated X-47A.

In 2002, USAF significantly expanded the operational requirements of the UCAV programme and reduced delivery times by 2 years, which resulted in excessive risk and cost increases. The US General Accounting Office, as well as DOD, recommended uniting efforts into a joint programme (J-UCAS) in 2003, which was later terminated in 2006 due to budget cuts and managerial divergences. However, in 2007 the J-UCAS programme was revived under the vague 'Next Generation - Long-Range Strike' project and the US Navy selected Northrop Grumman's X-47B 'cranked kite' design to be its proof of concept ${ }^{(14)}$, Fig. 1. The programme was subsequently labelled as UCAS-D for Unmanned Combat Air System-Demonstrator ${ }^{(15)}$ and its first flight took place in February $2011^{(16)}$. Despite on-going managerial divergences and changes in the programme's requirements $^{(17)}$, the development of the X-47B continued, and major goals such as catapult-assisted take-off, arrested recovery, and autonomous aerial refuelling were demonstrated ${ }^{(18)}$. In 2014, the Navy released a request for proposal (RFP) for the new Unmanned Carrier-Launched Airborne Surveillance and Strike (UCLASS) aircraft, with emphasis on affordability, endurance, and timely fielding, while operations in highly contested airspace were not emphasized ${ }^{(19)}$. More recently, the UCLASS project has been replaced by an unmanned tanker RFP, MQ-25 Stingray, designed to deliver robust refuelling capabilities for other combat strike fighters ${ }^{(20,21)}$.

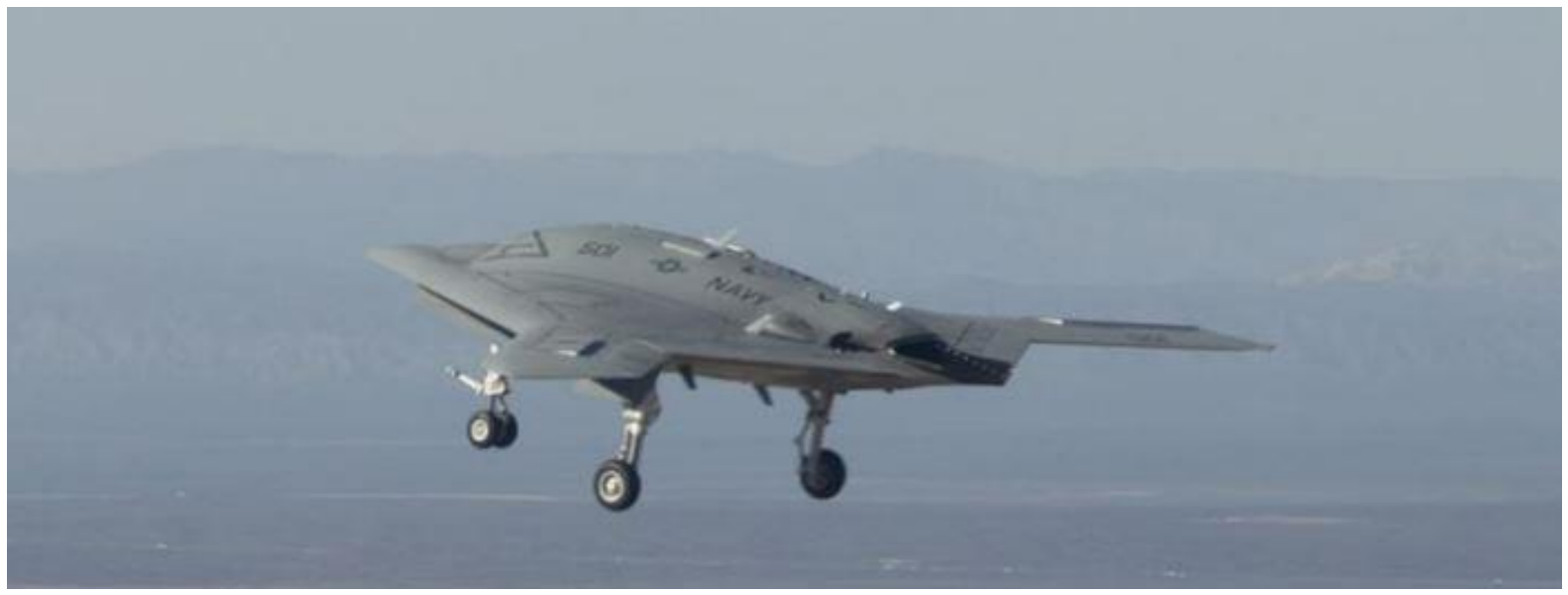

Figure 1. X-47B in flight.

On the other hand, Boeing continued with the development of their X-45C UCAV demonstrator, later named Phantom Ray, through self-funding and partnership with NASA, proving flight capabilities in 2011 (22). No information has surfaced since, and it is possible that the programme has been cancelled or gone 'black'.

\subsection{Neuron}

The Neuron UCAV demonstrator, Fig. 2, is a French/International programme led by Dassault Aviation launched in 2003, and it aims to evaluate advanced aerodynamics, stealth, navigation and control algorithms, as well as human factors and integration protocols for UCAVs in European military operations. It is expected to demonstrate air-to-ground capabilities, although it is not intended for real combat missions ${ }^{(23)}$. Neuron's first flight took place in 2012 over France, and it has recently completed basic combat capability and stealth evaluations $^{(24)}$.

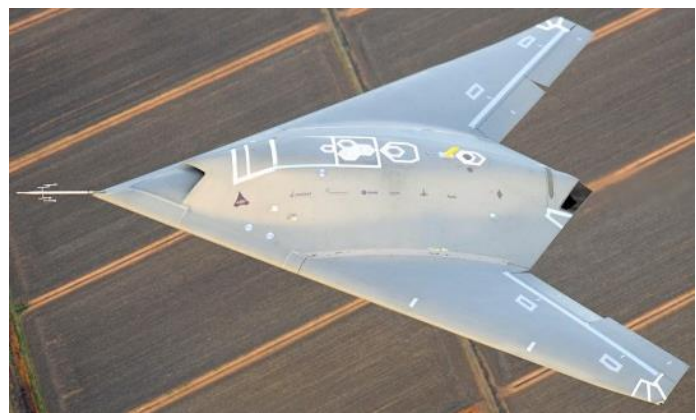

Figure 2. Dassault Aviation Neuron UCAV. 


\subsection{Taranis}

Taranis technology demonstrator, Fig. 3, is led by BAE Systems in collaboration with engineers from more than 250 companies. It was officially unveiled in 2010, and is designed to operate in sustained surveillance and intelligence gathering missions, as well as carrying out strikes in hostile territories through a combination of advanced aerodynamics, propulsion systems, and stealth ${ }^{(25)}$. Initial flight tests took place in late 2013 and early 2014 over the Woomera test range in Australia. Taranis is expected to eventually demonstrate supersonic combat capabilities ${ }^{(26)}$. Building on the knowledge gained from the Taranis and Neuron programmes, the British and French governments announced a cooperative effort in a $£ 1.5$ billion project to develop a 'future combat air system', the most advanced of its kind ${ }^{(27)}$.

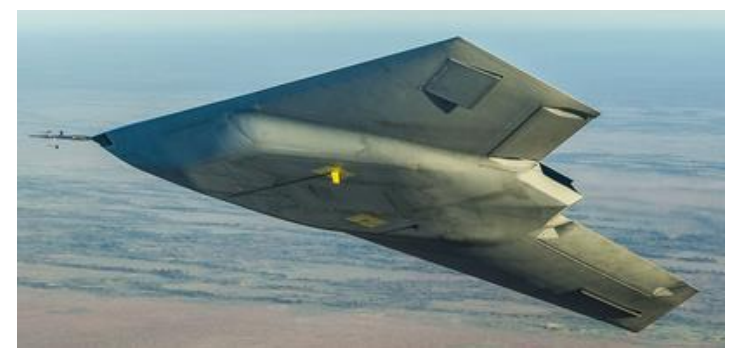

Figure 3. BAE Systems Taranis in flight.

\subsection{Others}

Several UCAV design projects have been reported to be under development in countries like Russia, India and China; however, concrete information is hard to come by. India's Aura UCAV, Fig. 4, is a lambda wing type configuration under development by the Indian Air Force and India's DRDO, expected to become operational by $2023^{(28)}$. Russia's MiG Skat UCAV project is believed to be cancelled ${ }^{(29)}$. The Chinese stealth UCAV demonstrator Lijian (Sharp Sword), Fig. 5, is believed to be currently under development, with taxi and flight tests taking place in $2013^{(30)}$. A comparison of existing and reported UCAV designs is shown in Table 1.

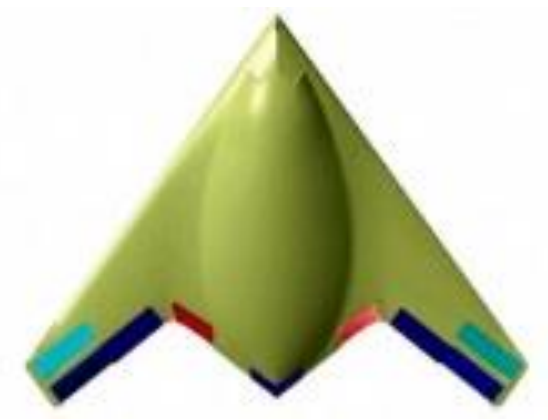

Figure 4. India's DRDO Aura UCAV early design.

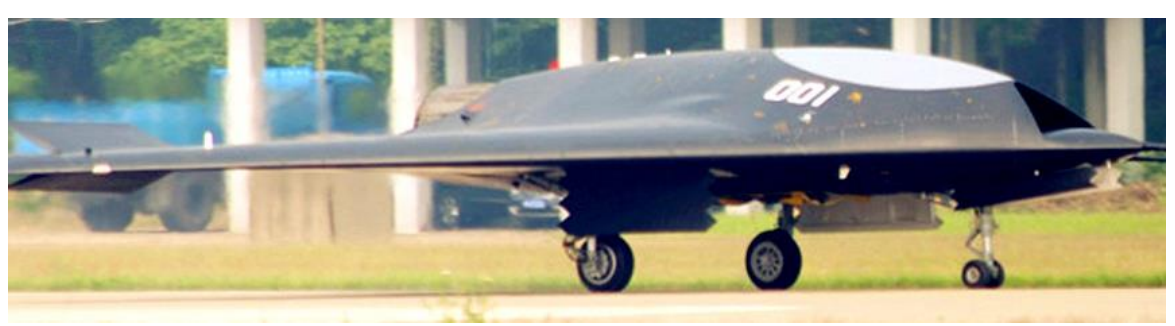

Figure 5. Chinese Lijian UCAV on runway.

Table 1

\section{Summary of technical specifications for existing or reported UCAV demonstrators}

\begin{tabular}{|c|c|c|c|c|c|c|c|}
\hline & & $\mathrm{X}-45 \mathrm{C}$ & X-47B & Neuron & Taranis & Lijian & Aura \\
\hline $\begin{array}{l}\text { Gross } \\
(\mathrm{kg})\end{array}$ & Weight & 16556 & 20215 & 7000 & 8000 & $\sim 10000$ & $<15000$ \\
\hline Empty & Weight & 8154 & 6350 & 4900 & NA & NA & NA \\
\hline
\end{tabular}


$(\mathrm{kg})$

\begin{tabular}{lcccccc}
\hline Range $(\mathrm{km})$ & 2414 & 3900 & NA & NA & NA & NA \\
\hline Cruise Mach & 0.8 & 0.9 & 0.9 & $\begin{array}{c}\text { Supersonic (to } \\
\text { demonstrate) }\end{array}$ & Subsonic & Subsonic \\
\hline Payload $(\mathrm{kg})$ & 2041 & 2000 & 460 & 2041 & $\sim 2000$ & $\sim 2000$
\end{tabular}

\subsection{TECHNOLOGY CHALLENGES}

The nature of UCAV operational requirements usually results in configurations with stealth considerations being prioritised. Common UCAV designs take the shape of tailless aircraft with swept, highly-blended geometries, leading to packaging, aerodynamic, and stability and control couplings that must be accurately evaluated from early design stages if superior manoeuvrability and performance are to be obtained. Furthermore, future capabilities are likely to extend on the operational speeds and manoeuvrability requirements to include supersonic regimes. Therefore, the understanding and correct evaluation of complex flight phenomena is a key aspect in modern and future combat aircraft design ${ }^{(31)}$.

\subsection{Stealth}

Stealth features can have detrimental effects in the aerodynamics, stability, performance, and overall system complexity of the aircraft. For example, a comparison between the X-47B and a configuration optimised for aerodynamics without taking into account stealth requirements ${ }^{(32)}$ shows a result of 10.84 drag counts at cruise for the optimised configuration compared to 122 drag counts for the X-47B, Fig. 6. Neutral stability was also achieved, compared to the negative $0.65 \%$ static margin reported for the original configuration. These results would have a significant impact on the range of the aircraft, as well as the required power during cruise, which translates into weight savings and further improvements in the overall performance of the aircraft. However, these results do not take into account packaging or performance constraints, which have a significant impact on the overall configuration.

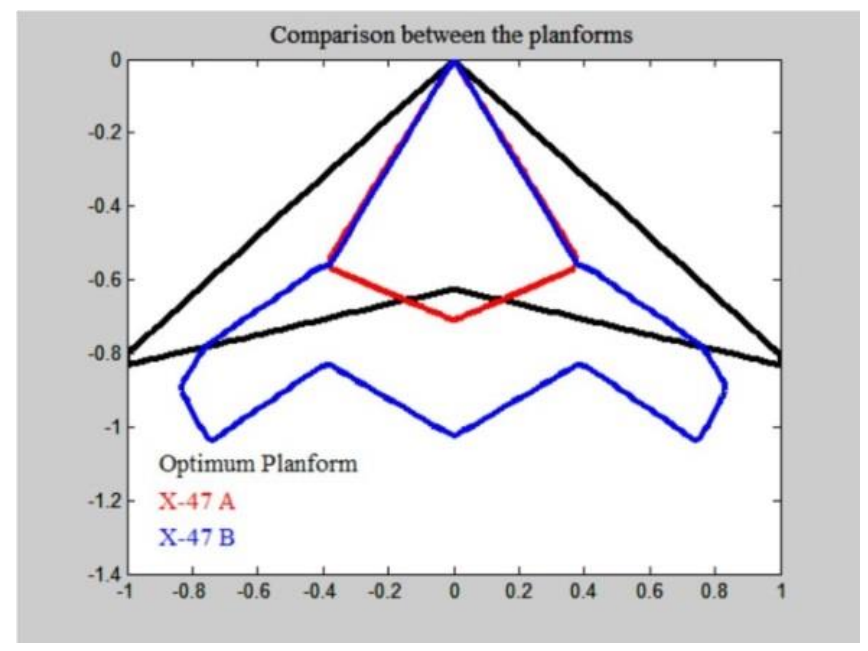

Figure 6. Effect of stealth requirements on UCAV configurations.

The design and development of the F-117 Nighthawk further illustrates the challenges of stealth aircraft. Firstly, it was determined that the main concern for low observability was the radar cross section in the nose-on aspect, followed by the tail-on and side aspects. Due to the radar signature prediction level achievable at the time, and as an limit value from the flight control engineers, the first design iteration took the shape of a diamond wing with a leading edge sweep of $72^{\circ}$ and trailing edge sweep of $30^{\circ}$, later called by the aerodynamics team as the hopeless diamond. However, this would return a large signature at a $30^{\circ}$ offset from the nose or tail aspect. This mandated a change in trailing edge sweep, and aerodynamics benefitted from decreasing leading edge sweep to $67.5^{\circ}$, trailing edge to $48^{\circ}$ and an overall increase in aspect ratio, which is very low at 1.65 . Also, payload had to be carried internally and engines had to be buried with provisions to control radar signature in both inlets and outlets. Communication antennas could only be operated during initial mission segments and retracted afterwards which limited communications with operating command. Lastly, radar absorbent material had to comply with high temperature requirements for anti-icing of the air data probes ${ }^{(33)}$.

Stealth involves numerous aspects such as visual and acoustic signature, radar cross section, infrared signature, and electromagnetic signature; achieving a truly undetectable aircraft seems improbable. Advances in radar and 
missile technologies question the relevance of current stealth technologies and design practices. For instance, development in passive radar systems can use the aircraft's actively generated signals such as navigation, identification and data transfer, as well as new illumination sources such as FM radio and digital TV signals to locate and track a target ${ }^{(34)}$. Similarly, new Surface-to-Air Missile Systems (SAMS) such as Russia's S-400 have velocities of up to $2000 \mathrm{~m} / \mathrm{s}$ and ranges of $400 \mathrm{~km}$ with advances in radar technology that resist jamming and other countermeasures ${ }^{(35)}$. Whether these developments render current stealth technology obsolete is still an open debate. Even so, modern aircraft designed for combat and intelligence purposes include stealth measures, especially for radar cross section and infrared signature reduction.

\subsubsection{Radar cross section (RCS)}

RCS is a measure of the amount of energy reflected in a certain direction when an object is illuminated by radar waves. Monostatic RCS is obtained when the transmitter and receiver are in the same location, while Bistatic and Multistatic RCS employ different locations for transmitter and receiver. To measure the real RCS of a complex object it is necessary to use an anechoic chamber, which ensures a 'quiet zone' where the electromagnetic field fluctuations are kept very low ${ }^{(36)}$; however, numerical RCS solutions based on physicaloptics approximations exist since the $1980 \mathrm{~s}^{(37)}$, more recent computational tools include RCSAnsys ${ }^{(38)}$ and POFACETS $^{(39)}$, amongst others.

Reducing an aircraft's RCS can be achieved through a combination of techniques such as geometric and aerodynamic shaping, radar absorbent materials (RAM) and structures (RAS), and electronic countermeasures. Monostatic RCS can be reduced by avoiding edges perpendicular to the incoming radar waves. Inclining and aligning edges will shift the direction of reflected beams away from the incoming source, as seen in Fig. 7 for a delta and a 'lambda' wing with aligned edges, so sweeping the wing has a direct advantage in terms of RCS signature. However, this strategy is not as effective for bistatic and multistatic radar systems. Besides sweeping the wing, highly blended geometries with extensive continuous curvatures can further reduce the total RCS signature, which can be seen in aircraft such as the B-2 stealth bomber, F-22 Raptor and the F-35 strike fighter. Figure $8^{(40)}$ shows how wing planform and aerofoil changes can influence the signature of UCAV configurations.

Carrying all weapons and payload internally will stop those elements from reflecting and scattering radar waves in multiple directions. Antennas, sensors and other protruding elements, such as geometry discontinuities due to doors, hatches, and control surface hinges, should be blended as much as possible to avoid further scattering sources $^{(41)}$.

Jet engine blades are a major source of reflected radar waves, a way of mitigating this effect is through a buried engine with a serpentine or S-shaped inlet duct, which not only blocks line-of-sight reflection but also has drag advantages since the engine is blended into the fuselage shape. However, the inlet design can cause adverse pressure gradients and separated flows if the geometry is not carefully designed ${ }^{(42-44)}$. To prevent flow separation in complex inlets, boundary layer suction and bleeds can be incorporated.
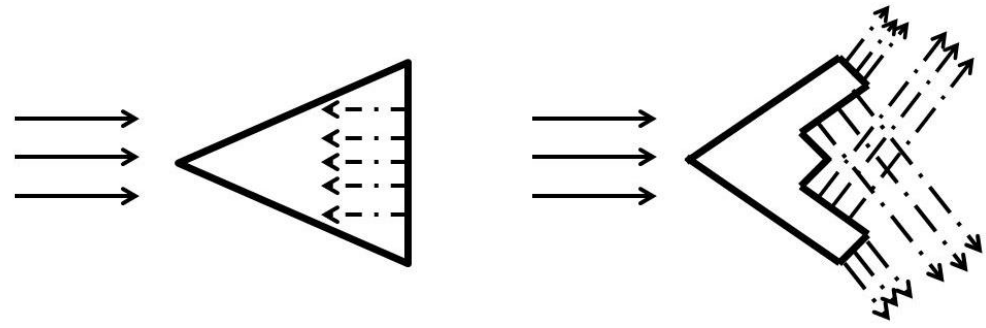

Figure 7. Radar wave reflection for perpendicular (left) and inclined/aligned edges (right).

RAM can be employed to further decrease an aircraft's RCS; new development in RAM coatings and radar absorbent paint (RAP) can vary their absorbent properties in response to a broadband of frequencies, this technology is called active frequency selective surfaces (AFSS) ${ }^{(45-47)}$. Similarly, composite matrices, like polyester and epoxy, can be enhanced with electromagnetic powders such as carbon black, ferrite, and carbonyl iron, to be used as structural components ${ }^{(48)}$. RAS can be load bearing or not, for instance, leading and trailing edge sections of the SR-71 Blackbird were composed of fiberglass, phenyl silane and silicone-asbestos to absorb radar waves while bearing no load ${ }^{(4)}$. Engine inlets should also be coated with RAM or RAP in order to further decrease RCS. For load bearing structures, it has been shown that a thin plate of glass/polyester enhanced with carbon black $(<3 \mathrm{~mm}$ ) can absorb approximately $90 \%$ of the incident electromagnetic wave energy in the Xband frequency $(\sim 3.7 \mathrm{GHz})$ while maintaining its structural integrity ${ }^{(49)}$. 

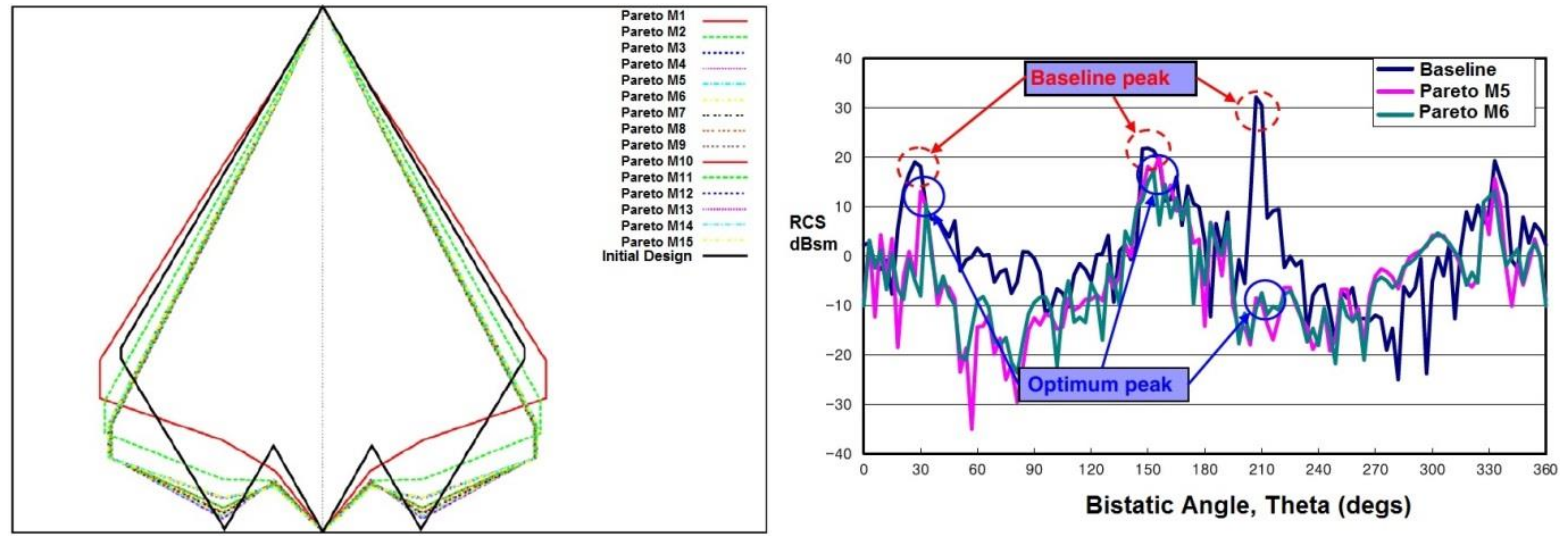

Figure 8. Aerodynamic and RCS optimisation for a diamond wing UCAV.

Electronic countermeasures, commonly known as jamming, are means of deceiving radar systems. Active jammers that send out specific or random signals to convey false information or to keep the channels busy at all times have been around since the 1950 s, they are effective but have high power requirements ${ }^{(50)}$. UCAVs flying in formation could use smaller jammers in a cooperative way to increase the overall jamming range and effectively conceal themselves in multiple radar environments ${ }^{(51)}$. Reactive jammers remain idle as long as no incoming signals are being detected, and start transmitting otherwise, which reduces the power required and the probability of being detected by passive radar systems. Their effectiveness has been assessed in wireless networks and satellite communication security ${ }^{(52,53)}$. More recently, digital radio frequency memory (DRFM) technology allows the recording of an incoming radio wave and its modification prior to being sent back in order to convey deceptive information ${ }^{(54)}$, and can be used to greatly reduce a vehicle's RCS signature and radar detection range ${ }^{(55)}$

\subsubsection{Infrared signature (IR)}

IR signature in an aircraft will make it susceptible to heat-seeking missiles, such as those used in MANPADS and air-to-air missiles. The main contributors to an aircraft's IR signature are the exhaust plume, aerodynamically heated skin, hot engine parts, and the reflection of sun, earth and sky shine, as shown in Fig. $9^{(56)}$. IR signature will determine the aircraft's lock-on range, which is defined as 'the locus of points around $a$ target where the missile's IR seeker locks-on to the target ${ }^{,(56,},{ }^{\text {p.233) }}$. This is not, however, a comprehensive criterion because it does not take into account target and missile speed, or the missile burn-out range. The 'lethal envelope' can account for these criteria, and it represents the area around a target where the probability of being hit by a missile is high ${ }^{(57)}$. Computational IR prediction packages like IRST ${ }^{(5)}$, NIRATAM $^{(59)}$, and SIGGE $^{(60)}$ rely on a combination of theoretical models, field measurements and infrared data sets, and can quickly estimate the IR signature of an object, such as an engine or an aircraft.

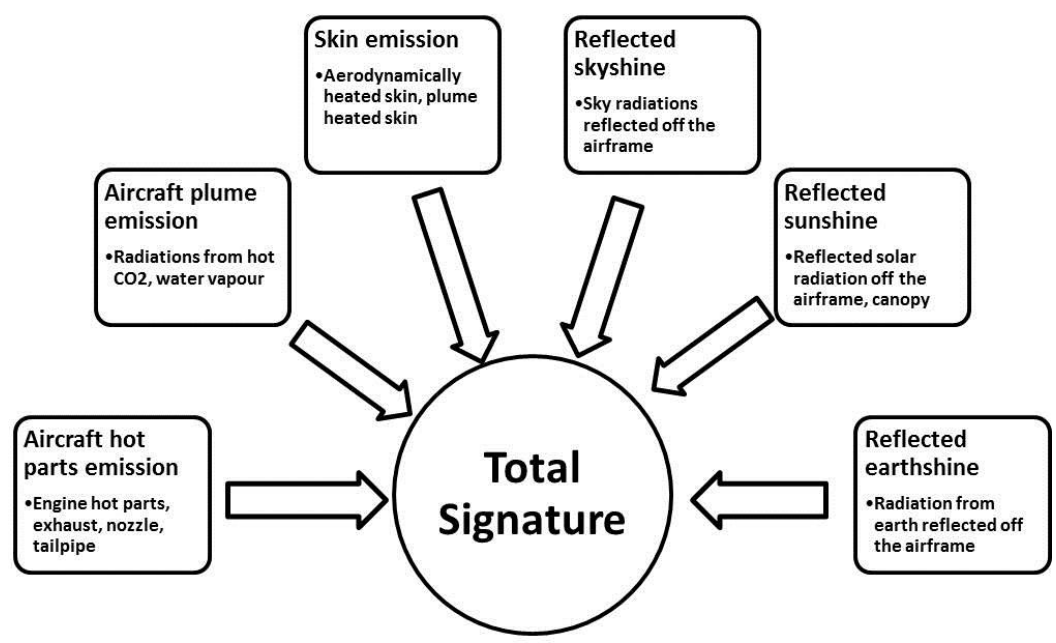

Figure 9. Contributors to an aircraft's total IR signature. 
IR countermeasures usually translate into weight and system complexity penalties. Passive countermeasures include: masking hot engine parts through geometry or structure modification, mixing hot exhaust gases with freestream air, reducing the reflectivity of the skin through certain coatings and paints, and modifying the skin temperature distribution through physical or chemical means such as liquid evaporation cooling. For jet engines, nozzles with large aspect ratios, defined as nozzle exit width over height, show significant reductions in IR signature when compared with circular nozzles due to pressure changes in the plume, as well as a more widespread plume which increases the mixture with cold ambient air, decreasing the overall length of the plume $^{(61)}$; ultimately, this leads to an important decrease in lock-on range, as high as 55\%. However, for large aspect ratio nozzles, penalties can be as high as a $10 \%$ reduction in available thrust.

Active IR countermeasures include: flares, IR jammers, missile approach warning systems, and a 'sacrificial structure' which attracts the missile away from any vital structural elements and systems by using an IR decoy, such as an IR lamp mounted on a supporting structure ${ }^{(62)}$.

\subsection{Aerodynamics and stability}

The use of sweep was originally applied in order to delay drag divergence experienced at high subsonic Mach numbers, and thus improve the aerodynamic performance in transonic regions. This is achieved due to the lower normal velocity component along a wing section for a swept wing, which is equivalent to the cosine of the sweep angle. For instance, for a particular lift condition at transonic cruise speed $(\mathrm{M}=0.85)$, increasing the sweep of a BWB aircraft from $20^{\circ}$ to $40^{\circ}$, shows an $80 \%$ increase in lift over drag ratio. This is due to a significant reduction in wave drag by the decreased intensity of local sonic flow over the geometry ${ }^{(63)}$. The reduction in perpendicular flow also results in a loss of total lift produced varying proportionally to the cosine

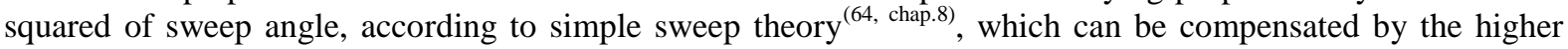
velocities achievable. However, it has been shown that this does not agree well with experimental results, as well as not being able to account for the increment in lift due to leading edge vortices ${ }^{(65)}$.

\subsubsection{Delta wing aerodynamics}

The flow field of swept configurations is characterised by the formation of leading edge vortices as shown in Fig. 10. The low pressure at the vortex core usually translates in beneficial lift characteristics through suction, due to low pressure in the vortex cores, and boundary layer separation delay ${ }^{(66)}$. These benefits persist until the AoA is high enough for vortex breakdown to occur, which is characterised by rapid flow expansion, sudden change in the velocity field and large fluctuations in the vortical structure ${ }^{(67)}$. For low sweep delta wings, often called non-slender delta wings $\left(\Lambda_{L E}<55^{\circ}\right)$, vortex structures develop at lower angles and much closer to the wing surface, resulting in strong interactions with the boundary layer, strong dependence with Reynolds number and leading edge radius, double vortical structures, and a less violent vortex breakdown process ${ }^{(68)}$. Vortex-related issues applicable to UCAV configurations ${ }^{(69)}$ include antisymmetric vortex breakdown location, vortex reattachment causing wing rock, and the interaction between manoeuvring and vortex instabilities, which can impact the development flight control laws.

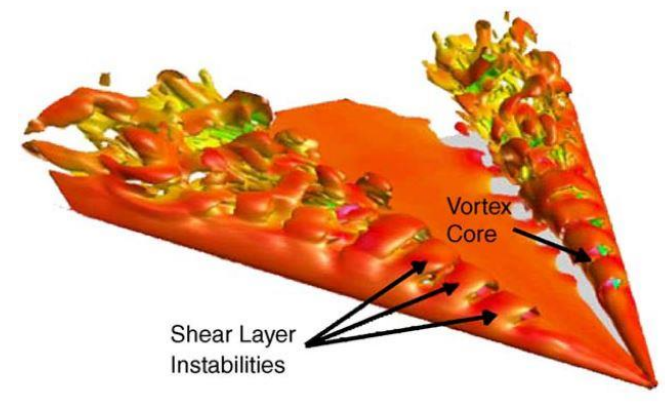

Figure 10. Instantaneous vortex structure for a $\Lambda_{L E}=50^{\circ}$ delta wing.

\subsubsection{Validation of numerical methods applied to UCAV designs}

Unsteady aerodynamics represents a major challenge for highly manoeuvrable UCAV configurations, impacting the development of flight control systems, and if not identified during the early design process can significantly increase cost and risk during flight testing. For this reason, high-fidelity aerodynamic tools and models are required during the early design process of UCAVs.

Extensive validation efforts have been undertaken by NATO's Research and Technology Organization (RTO)

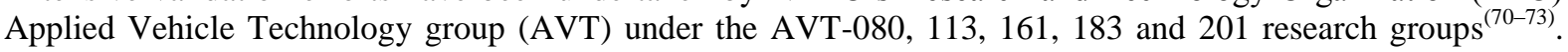


Quantitative and qualitative data were obtained for a variety of configurations ranging from diamond to lambda wing type 'generic UCAVs' through methods such as pressure taps, PSP, smoke and laser sheet, oil flow visualisation, LDV and PIV. Similarly, a variety of numerical solutions, such as structured and unstructured grids solving Euler, RANS, DES and LES governing equations for steady and unsteady state conditions, with several turbulence models were investigated. Additionally, analytical and semi-empirical models were developed to evaluate the structure and behaviour of vortex breakdown. Variations in leading edge geometry and dependence on Reynolds number were also investigated.

Figure $11^{(74)}$ shows the results from AVT-61 numerical aerodynamic validation efforts over a generic UCAV design with a leading edge sweep of 53 degrees, known as SACCON. Experimental data are compared to numerical simulations for different turbulence models and grid structures for AoA from $15^{\circ}$ to $22^{\circ}$ due to computational resources available. It can be seen that the predicted lift and drag coefficients (solid and dashed lines) show good agreement with the experimental data; however, the predicted pitching moment coefficient shows large disagreements for AoA above $20^{\circ}$. This relates to the complex vortex topology present over the UCAV. At AoA higher than $20^{\circ}$, the vortex topology suffers a significant change; the tip vortex shown in Figure 11 (top left) is replaced by a large primary vortex (Fig. 11 top right) covering most of the 'outer wing' geometry. The same difficulty to predict pitch moment coefficient is reported ${ }^{(75)}$ even when expensive numerical solutions are applied. The correct prediction of vortex breakdown has been shown to be a very difficult task, and

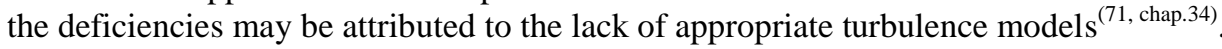

Similar validation efforts have been applied to Boeing's 1301 and 1303 generic lambda wing designs ${ }^{(76)}$. Figure $12^{(77)}$ shows the evolution of streamlines with respect to angle-of-attack, violent vortex breakdown can be seen for AoA higher than $15^{\circ}$. Results also show that a round leading edge has coupled effects with Re, while sharper geometries are insensitive to $\mathrm{it}^{(78,79)}$.

Lower fidelity methods have also been evaluated. These methods consist on potential flow solvers with compressibility and boundary layer corrections (VSAERO, LIFTING_LINE), panel methods enhanced with leading edge vortex separation and vortex breakdown models (Nangia-Aero-Panel, dwfs Panel), and vortexlattice enhanced with empirical models (Tornado VLM, SHAMAN) ${ }^{(80,81)}$. Results show good agreement with lift and drag coefficients for low to moderate AoA; however, results for pitching moment coefficient vary significantly due to non-linear flow phenomena that low order methods cannot fully predict. This limits the applicability of such methodologies to the early conceptual design stage.
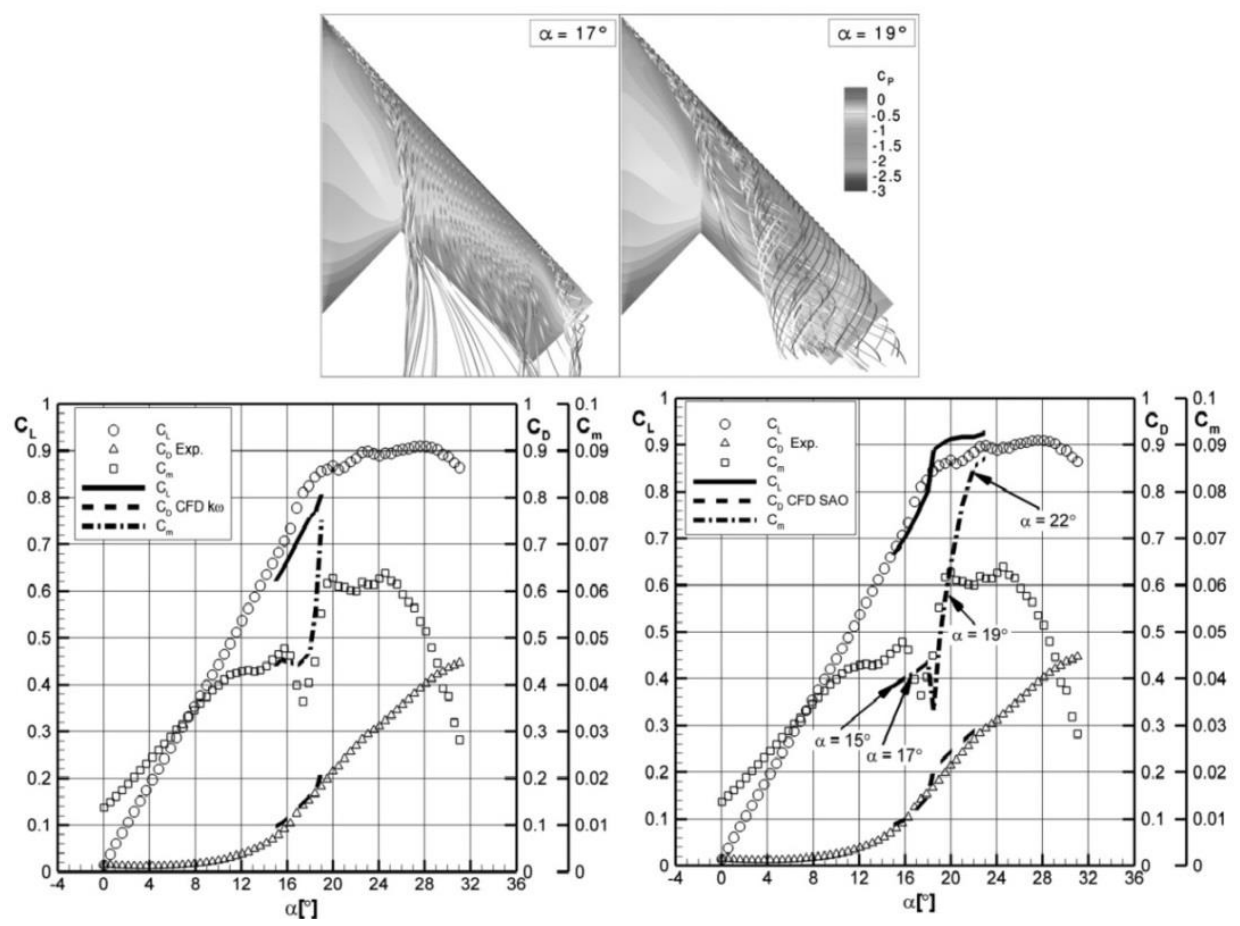

Figure 11. Surface pressure distributions and streamlines on the upper side of SACCON for AOAs of $17^{\circ}$ and $19^{\circ} . \mathrm{M}=0.15$ and $\mathrm{Re}=1.6 \cdot 10^{6}$ (Top). Experimental results compared to numerical simulations for Wilcox-k- $\omega$ (left) and Spalart-Allmaras (right) turbulence models. 


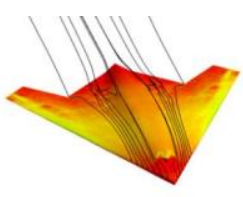

a) $\alpha=5^{\circ}$

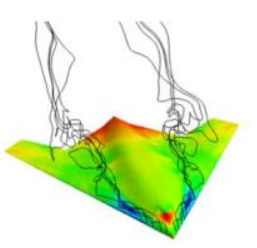

d) $\alpha=20^{\circ}$

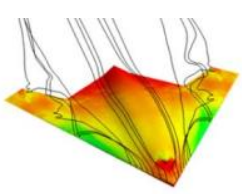

b) $\alpha=10^{\circ}$

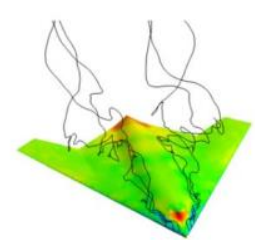

e) $\alpha=25^{\circ}$

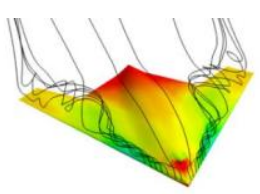

c) $\alpha=15^{\circ}$

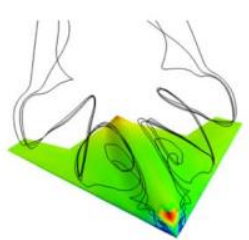

f) $\alpha=30^{\circ}$

Figure 12. Flow field evolution for 1301 UCAV.

\subsubsection{Stability and Manoeuvrability}

Low speed and high attitude flight is particularly problematic for UCAV type configurations. Low speed wind tunnel testing of UCAV $1303^{(82)}$ shows the pitch-up behaviour associated with UCAV configurations, Fig. 13, which limits the maximum usable incidence of the aircraft to around 10 degrees. One of the consequences of a low value of maximum incidence is an increase in required speeds for take-off and approach, which could impose higher demands on the engine size, possibly driving the entire configuration. Combinations of twist and camber can be used to increase the maximum incidence and delay the pitch-up behaviour to the point where modern flight control systems can provide enough control in the pitch-up region.

The vortex flow field of UCAV configurations has a strong influence on control surface effectiveness, as demonstrated experimentally for longitudinal motion ${ }^{(83)}$, and for lateral motion ${ }^{(84)}$ with conventional control surfaces, i.e. inboard flaps and outboard ailerons, which already require high control power due to the short moment arms of such configurations. For non-conventional control surfaces, simulations including belly flaps and canards show that different control surface combinations can provide the required lift and trim values required for carrier-based operations, with penalties in stealth, mass, and system complexity. The trade-offs for choosing the right combination can be appreciated in Figure $14^{(85)}$, where the actuation of belly flaps or canards only cannot achieve the required increment in lift coefficient and must be combined with other control surfaces. Other studies make use of non-conventional control surface arrangements, such as slot-spoiler deflectors (SSD), all-moving wingtips (AMT), and clamshell elevons, as shown in Figure $15^{(86)}$.

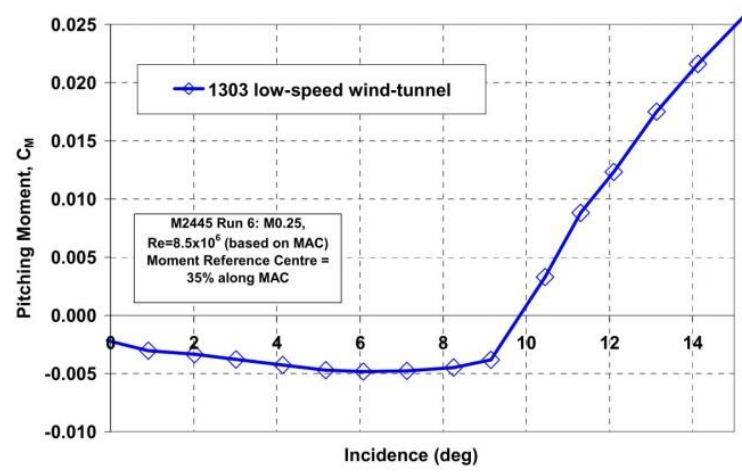

Figure 13 - Low speed pitching moment of 1303 UCAV $(M=0.25)$.

Other types of control effectors being studied are active control actuators, which modify the flow and pressure distribution over the aircraft surface. Pairs of pneumatic active flow control actuators are used to effectively provide lateral-directional control of a delta wing UCAV while also reducing drag for particular attitudes (lift coefficient remains unchanged, which leads to an increase in aerodynamic efficiency and extended range), which could potentially balance the costs of the engine 'bleed' that these type of actuators requires ${ }^{(87)}$. 


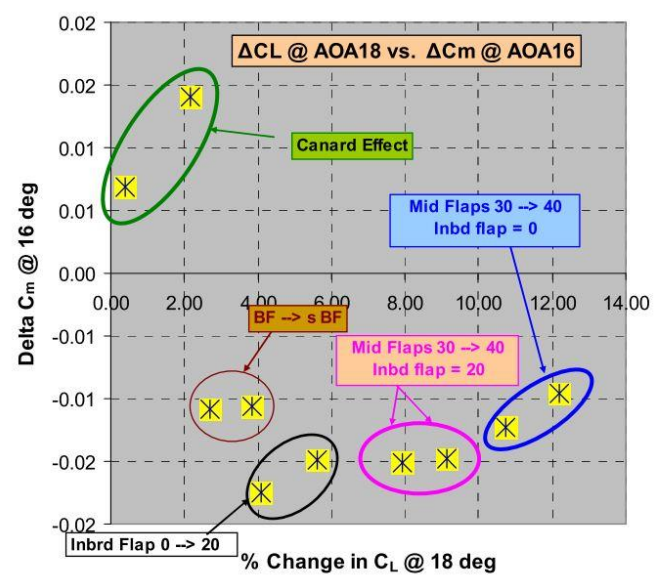

Figure 14. Trade-off comparisons between different control surface combinations for a BWB type UCAV.

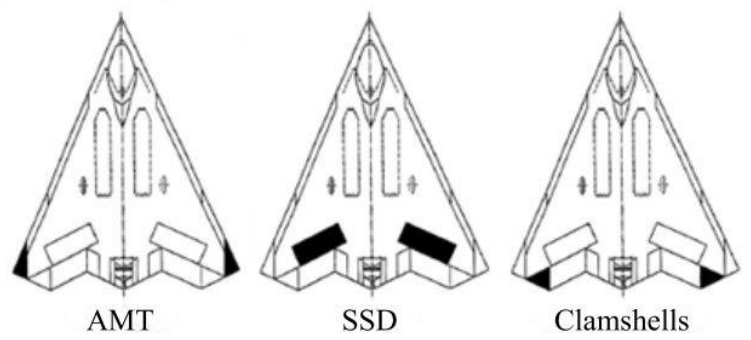

Figure 15. Non-conventional control surface arrangements for a delta wing fighter.

At transonic speeds and high AoA, conditions easily encountered during combat manoeuvres, the vortex dominated flow field interacts with local sonic flow which forms complex shock wave systems at Mach numbers as low as 0.7 . These shock waves affect the formation of vortices and can significantly increase the flow separation extension as Mach numbers approach sonic condition. The extent of shock-induced separation can be attenuated by tailoring the twist and leading edge radius distribution along the span of the configuration $^{(88)}$.

\subsection{Structures}

\subsubsection{Composite materials}

UCAV designs optimised for stealth and aerodynamic efficiency result in complex geometries, which makes them ideal candidates for implementing the use of composite materials and advanced manufacturing techniques such as the foam matrix core process used in the X-45A wings ${ }^{(89)}$. In the case of the $\mathrm{X}-47 \mathrm{~B}, 90 \%$ of its surface is made out of composite skins, as well as a significant part of its outer wing structure ${ }^{(90)}$. New high-temperature composites based on polyimide, bismaleimide and cyanate ester matrices are being used in the 'hot zones', such as engine components and possibly in future high-speed vehicles where aerothermal phenomena are important design constraints ${ }^{(91,92)}$. The main advantage of integrating composite materials is a significant weight reduction with equivalent or superior stiffness properties. Advanced manufacturing techniques also reduce the number of assembly components further reducing weight and overall complexity. Furthermore, a wide variety of sensors can be directly embedded into the composite plies in order to provide in situ structural health monitoring capabilities. Optical sensors such as fibre Bragg gratings have been shown to accurately detect and monitor fatigue crack growth in composite adhesive joints when compared to other techniques such as ultrasonic testing; for a comprehensive review of optical sensors in composite structures see ${ }^{(93)}$.

One of the main disadvantages of switching from electrically conductive metallic alloys to insulating composite materials is the higher probability of lightning strike damage, which can cause embrittlement, delamination, resin evaporation, and finally structural failure. Current lighting strike protection (LSP) in composite structures is provided by bonding a mesh of aluminium or copper to the outer composite surface, providing enough electrical conductivity. However, this mesh increases structural weight and diminishes the weight saving advantages of composite airframes. Possible future LSP solutions include carbon-based materials such as 
Carbon nanotubes, graphene and graphite added to the composite matrix to increase it mechanical, thermal, and electrical properties. Additionally, metallic coats can be applied to composite structures in order to achieve the required thickness and conductivity for sufficient LSP levels. Other challenges of LSP include reparability and maintenance. A review of regulations concerning lightning strike, as well as prospects for metallic and carbonbased materials and techniques for advanced LSP solutions can be found in ${ }^{(94)}$.

Another important challenge for composite structures is impact damage resulting in composite delamination. Low velocity impact damage can result from foreign object damage and maintenance errors (such as tool drops). Delamination effects are particularly critical for structural components loaded under compression because buckling behaviour can propagate the extent of delamination cracks, which in turn severely affect the mechanical properties leading to premature collapse of structures, as shown in ${ }^{(95)}$ for single and multidelamination composite panels. For this reason, it is important to develop analysis and management strategies for delamination growth prediction. Numerical delamination growth monitoring strategies developed in ${ }^{(96-98)}$ for large deformations and non-linear geometrical effects, as well as contact influence, confirm a significant reduction in global buckling load for composite panels when delamination is present.

Finally, combat aircraft often suffer battle damage, which can take the form of holes from ballistic damage or shrapnel damage on the skin of different parts of the aircraft. Generic composite repair techniques investigated by NASA and Northrop Corporation during the 1970s and 1980s showed that structural integrity of composite structures could be restored without the use of expensive or special tools ${ }^{(99)}$. More stringent aircraft battle damage repair specifications limit the applicability of repair techniques such as prepreg tape and film adhesive due to their need for freezer storage. Hand lay-up methods can be used but introduce large porosities due to trapped air and resin reaction gasses. Pre-cured hard patches bonded with adhesive paste can be used but their low carrying capability also limits their applicability. A promising solution is vacuum infusion repairing. By using portable curing units, low viscosity resins, and a novel brittle-bond area reinforcing technique, vacuum infusion has been shown to be suited for aircraft battle damage repair of composite structures ${ }^{(100)}$.

\subsubsection{Aero-structural interactions}

The interaction between a flexible structure and the complex vortex topologies characteristic of delta wings has been demonstrated experimentally ${ }^{(101)}$ and numerically ${ }^{(102)}$ for slender and non-slender wings concluding that vortex flows can cause wing buffeting and large aeroelastic responses. Therefore, it is necessary to incorporate aeroelastic considerations during early design stages. This is most commonly achieved by using numerical simulations packages linked between aerodynamic and structural computations. MSC NASTRAN includes a doublet lattice method that provides pressure coefficients with which aerodynamic loads can be applied to a structural mesh, as shown for a UCAV structural optimisation study ${ }^{(103)}$. Similarly, CFD and FEM computations are linked through DLR's in-house TAU code for steady aeroelastic analyses of a generic UCAV configuration, revealing its behaviour with changes in Mach and $\mathrm{AoA}^{(104)}$, as shown in Fig. 16. Results show that aeroelastic deformation has significant effects in the development of vortex flow topology at high speeds and angles of attack, and thus in the development of lift and drag coefficients. Examples of aero-structural coupling strategies for the application of manoeuvre loads on a generic flying-wing UCAV structure model is shown in a DLR study, including control surface trim effects ${ }^{(105)}$.
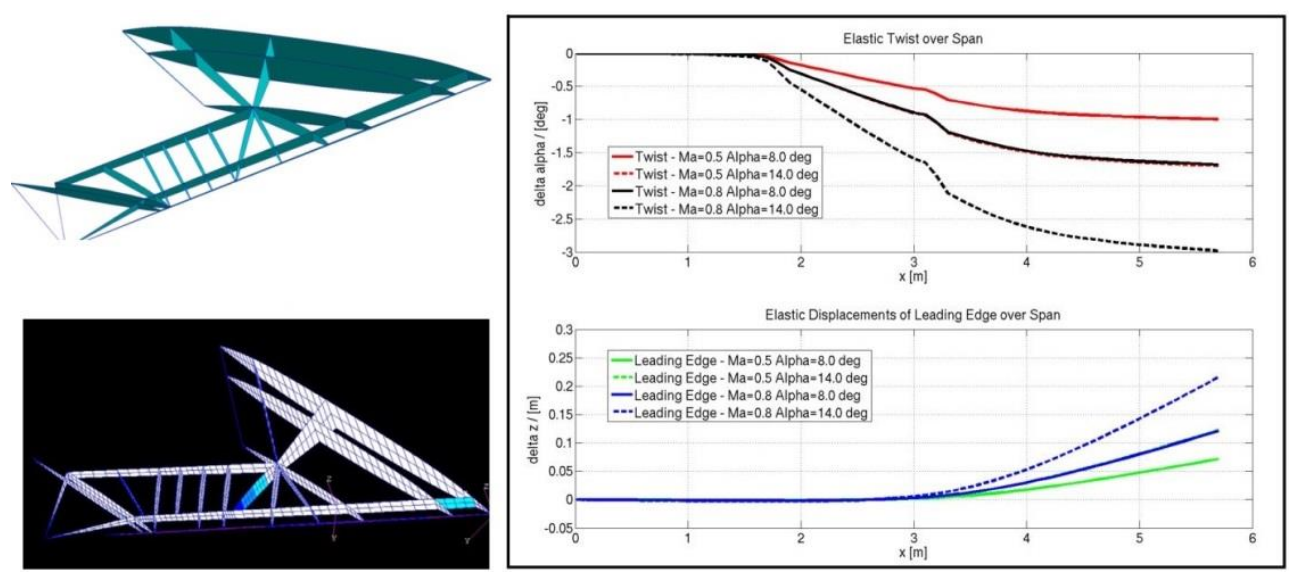

Figure 16. Aeroelastic deformation of a UCAV configuration at various Mach numbers and AoA. 


\subsubsection{Other structural considerations}

Some operational constraints have a direct impact on the structure of the vehicle. For instance, some supportability requirements mandate the transport of UCAVs on military cargo aircraft such as the C-5 or C-17, which limits the maximum wingspan to around 5.5 meters, that along with long-term storage (up to 10 years) requires a modular design, as seen in Fig. 17 by the truncated wings ${ }^{(106)}$, while also emphasizesing the need for careful material selection.

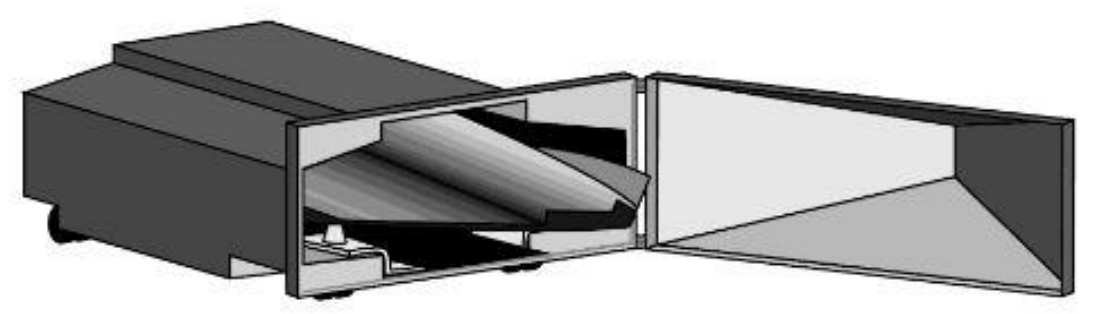

Figure 17. UCAV long-term, humidity-controlled storage concept.

\subsection{Packaging}

Packaging is a multidisciplinary challenge which impacts the aerodynamic, stability, performance, and operational capabilities of the vehicle, and more so for highly constrained vehicles such as UCAVs. To illustrate the point, longitudinal stability is enhanced by densely packing the nose area of a lambda wing UCAV with some systems and avionics components, as seen in Fig. $18^{(107)}$. Similarly, Storm Shadow UCAV shows an awkward and complicated landing gear retraction for both the nose and main landing gear, in order to fully accommodate the avionics and systems required, Fig. $19^{(108)}$. Tight packaging can also have significant effects on aircraft maintenance and operational costs. The detailed transparency of Neuron UCAV shown in Fig. 20 ${ }^{(109)}$ exemplifies this issue. The complex and stealthy engine inlet design can also be seen quite clearly.

Internal weapon bays are not only a packaging issue, but they can also result in severe aero-acoustic interactions which can compromise the structure of the aircraft, and any equipment contained in them, as well as having adverse performance and handling characteristics when activated at high speeds ${ }^{(110)}$.

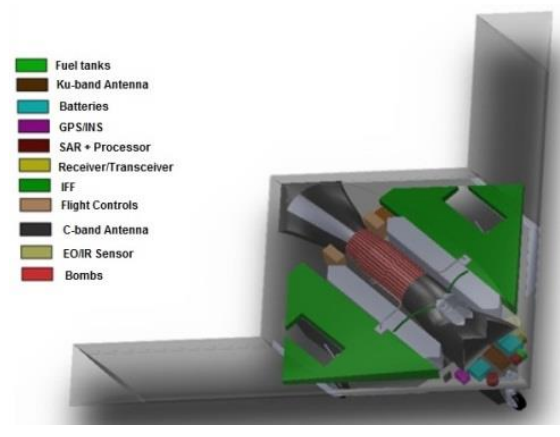

Figure 18. Cerberus UCAV systems arrangement.

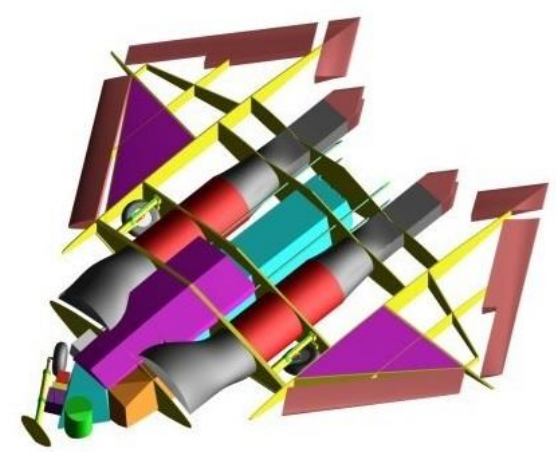

Figure 19. Storm Shadow UCAV internal arrangement. 


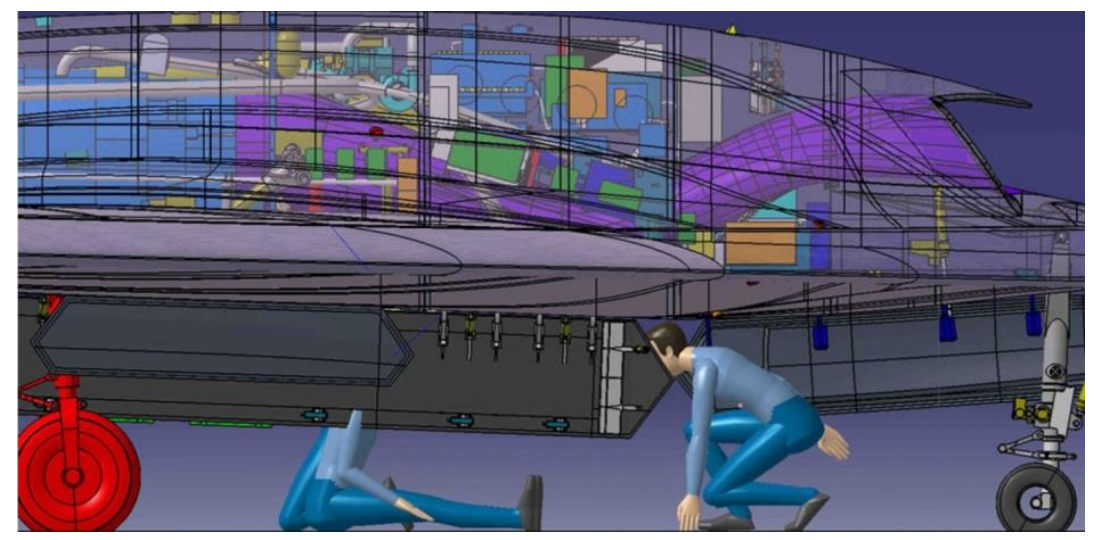

Figure 20. Neuron CAD model transparency; a high density packaging area can be seen above the engine inlet.

During the early conceptual design process the class shape transform (CST) proposed by Kulfan ${ }^{(111)}$ can be used as an efficient geometrical parametrisation strategy, and can be employed to include volumetric and packaging constraints during multidisciplinary design optimisation of BWB aircraft ${ }^{(112-114)}$.

\subsection{UCAV conceptual design studies}

The vast majority of UCAV conceptual design studies found in literature ${ }^{(40,80,82,108,115-125)}$ take the form of flying wing configurations fulfilling ground strike type missions, with cruise speeds in the transonic region; from Mach 0.7 up to Mach 0.85. Low observability requirements, most commonly in terms of RCS considerations, often dominate the configuration choice in terms of sweep and absence of vertical control surfaces. Dash or ingress/egress segments take place at low to medium altitudes $(100 \mathrm{~m}$ up to $5 \mathrm{~km})$ for short distances and at higher speeds well into transonic regimes, usually close to Mach 0.9, some allowance for combat manoeuvres is occasionally specified during the dash and weapons release segments, which often drives the maximum normal acceleration manoeuvring limit up to values of $7.5 \mathrm{~g}$. Payloads go from $400 \mathrm{~kg}$ up to 2000 $\mathrm{kg}$, always carried internally due to low observability constraints. This type of mission can be generalised as shown in Figure 21. Cruise segments are usually specified in terms of optimum speed and altitude for fuel savings.

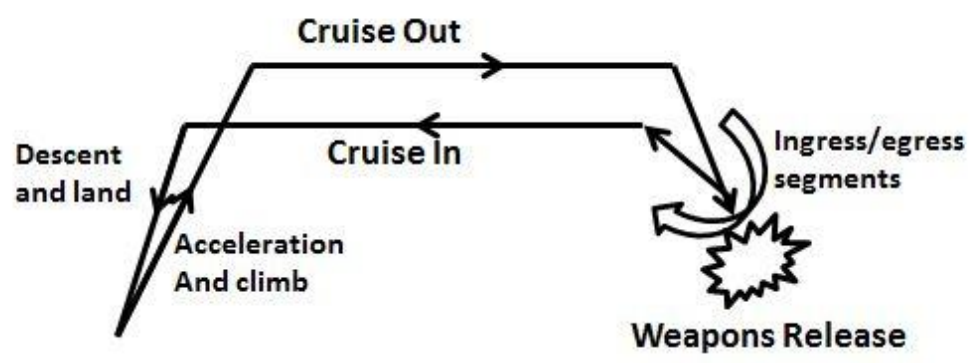

Figure 21 - Strike mission schematic

Conceptual design methodologies commonly include a wide range of fidelity levels for multidisciplinary design analysis and optimisation (MDAO), from empirical models and regression constants to surrogate models through response surface methods derived from high-fidelity data resulting from wind tunnel and numerical computations. In most cases, a particular baseline configuration undergoes an optimisation study in order to expand mission capabilities, where the driving requirements are often mission combat radius, payload mass, and field performance requirements. As shown in the 1303 UCAV studies ${ }^{(82,115)}$, poor aerodynamic and stability performance, namely the low value of maximum allowable incidence prior to pitch-up behaviour occurs, combined with field performance requirements often drive the entire size of the configuration. Field performance requirements impose larger engines, more fuel, and a larger centre section length (for internal engine housing) which increases structural mass, further driving the engine requirements higher. Stability constraints drive the UCAV design shown in ${ }^{(122)}$ where an inverted engine installation is investigated. It is shown that this option increases the lift coefficient in order to comply with pitch trim requirements while also improving lift at lower speeds; however the engine performance is severely affected due to the complex inlet geometry, resulting in an oversized engine. 
A different approach is taken in the pre-conceptual design survivability analysis presented in ${ }^{(124)}$, where flight speed and manoeuvring load factor are the main design outcomes. In this study, the mission requires the UCAV to hit a SAM missile launch site. A target volume is determined by combining SAM performance data, UCAV flight path, speed and evasive manoeuvring capabilities, obtaining a probability of kill, which is defined as the combined probability of the UCAV being hit, and the probability of kill when hit. Figure 22 shows Pareto solution sets for probabilities of success (as outcomes of uncertainties in the modelled performances of both UCAVs and SAM systems) expressed in terms of standard deviations $(\sigma)$ imposed on particular kill probabilities as a function of aircraft performance. From the figure, a probability of success of $99.99 \%(3 \sigma)$ limits the aircraft performance to flight speeds of Mach 1.32 up to 1.5 and instantaneous turn rate from $11.4 \mathrm{~g}$ to $13.1 \mathrm{~g}$; this solution also shows a maximum kill probability of $10 \%$. In this way, a kill probability threshold can be defined as a design requirement, flight performance can be determined, and the designer can incorporate such performance levels during the early conceptual design process.

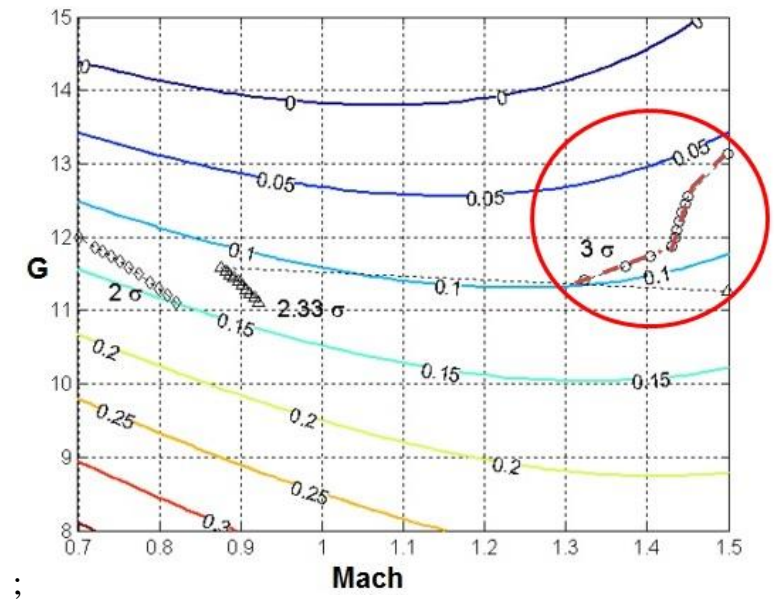

Figure 22 - Pareto solution sets for particular kill probabilities vs flight speed and instantaneous turn

An interesting technology level impact study is shown in $^{(123)}$ for a UCAV design which is not a flying wing or BWB type but rather closer to an advanced manned fighter design. This study can integrate 'advanced technology scenarios' for particular disciplines to determine the impact in the overall design. As an example, a higher use of composite materials reduces structural mass, improves performance but also increases development costs significantly. Large sensitivity analyses can be generated using this procedure, which reveals important information for decision makers in terms of particular technologies that require accelerated development efforts.

A multi-objective optimisation study aimed at a strike $\mathrm{UCAV}^{(40)}$ shows the type of trade-offs designers can expect when considering different mission segments and their influence on performance and structural parameters. The objectives are (1) maximise aerodynamic efficiency at cruise, (2) maximise aerodynamic efficiency at transonic, low-altitude ingress/egress, and (3) minimise wing bending moment during ingress/egress segments. Potential flow solvers FLO22 and FRICTION provide aerodynamic data, and the design inputs are wing planform and aerofoil control points. A multi-objective evolutionary algorithm coupled with a Pareto tournament strategy is used to obtain the non-dominated Pareto fronts, as shown in Figure 23. It can be seen that lower values of wing bending moment (Obj3) correspond to lower values of lift-to-drag ratio at both cruise and ingress/egress segments, which can be expected due to the lower lift being produced. 

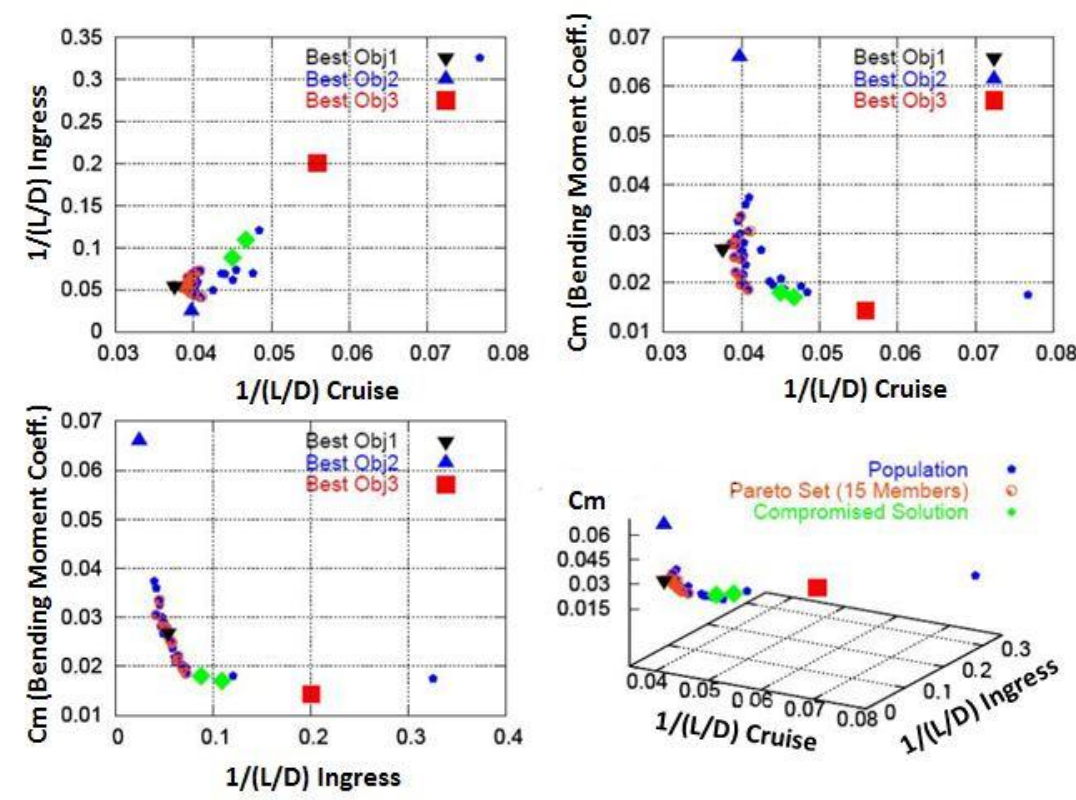

Figure 23 - Pareto optimal fronts for UCAV wing/aerofoil optimisation

\subsection{AIRWORTHINESS AND NAVIGATION}

Some of the key challenges identified in the operational constraints and certification of unmanned vehicles are: safety strategies for autonomous navigation such as detect and avoid capabilities, human systems integration, privacy concerns held by the public, and security implications. To overcome these difficulties proper standards and minimum operational requirements for all classes of unmanned vehicles must be developed ${ }^{(126)}$.

\subsection{Integration into the airspace}

The first efforts towards UAV regulation and integration into civil airspace systems date back to 1991, with the HALE UAV certification roadmap undertaken by the FAA along with partners in academia and industry. Today, certification for unmanned systems are still temporary measures all across the globe ${ }^{(127)}$.

In the United States, UAS operations are authorized case-by-case through a special airworthiness certificate under the experimental aircraft category and a certificate of authorization $(\mathrm{COA})^{(128)}$ as mandated by Order $8130.34 \mathrm{C}^{(129)}$. Up to October 2016, a total of 74 COAs have been granted by the FAA to government institutions such as the Air Force Research Laboratory, law enforcing agencies such as the Customs and Border Patrol, universities and research centres such as the Washington State Department of Transportation, and environmental agencies such as the U.S. Department of Agriculture - Forest Service ${ }^{(130)}$.

In the UK the ASTRAEA programme seeks to include unmanned aircraft in all classes of airspace without restrictions or special conditions by developing key enabling technologies and procedures ${ }^{(131)}$. For the rest of Europe, EASA along with JARUS must regulate civil operations of UAVs over $150 \mathrm{~kg}$ under Regulation (EC) No 216/2008, which dictates how standards and certification policies must be generated ${ }^{(132)}$. For military purposes, NATO's STANAG 4671 establishes baseline airworthiness standards for the design and construction of UAVs ${ }^{(133)}$.

Chinese regulation allows any UAV weighing less than $7 \mathrm{~kg}$ to be flown without any kind of license or certificate, UAVs between 7 and $116 \mathrm{~kg}$ require a license from the Civil Aviation Administration of China (CAAC), and for UAVs heavier than $116 \mathrm{~kg}$ to be operated in the airspace where manned aircraft fly, operators must have a pilot license and authorization from the CAAC. This however, seems to be an initial measure towards integrating unmanned operations into the airspace ${ }^{(134)}$.

The impact of large unmanned aircraft in the civil airspace is currently being evaluated through large scale simulations, human and hardware in the loop tests, and flight tests with virtual and real UAVs ${ }^{(135-137)}$. The test flight shown in Figure 24 represents the UAV path in an airspace sector where simulated, historical and realtime air traffic was included. These simulations also allow engineers and policy makers to compare certain safety strategies, definitions, and metrics such as 'well clear', 'separation assurance', and other separation 
standards, which will in turn feed into the regulatory frameworks in the form of minimum performance and operation requirements.

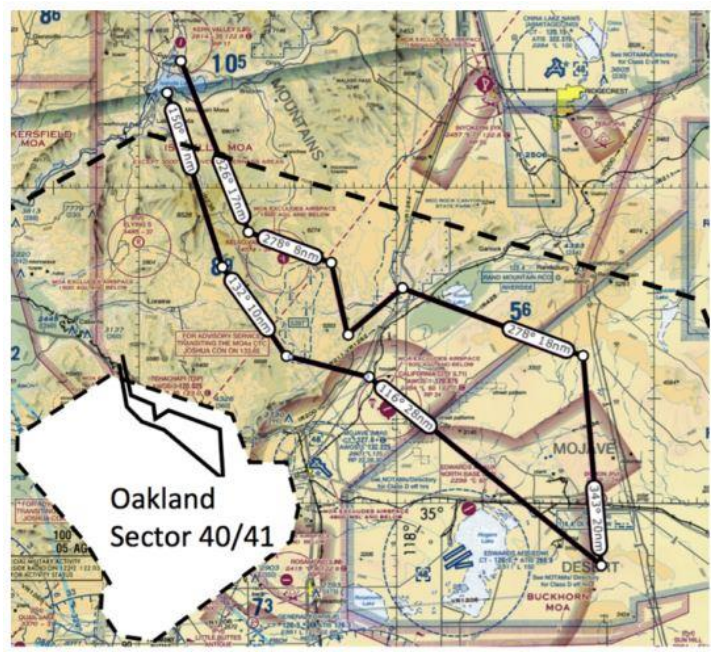

Figure 24. UAV flight path mapped from restricted airspace sector $40 / 41$ into virtual airspace for flight test demonstration.

The continuous development of small, light-weight UAVs and their increased areas of application require new approaches towards unmanned operations. NASA's UAS Traffic Management project (UTM) seeks to develop concepts and technologies that enable operations in low altitude, variable-risk areas, from rural to urban, through a combination of live operations and virtual human in the loop simulations. This project will also develop key software components to gradually increase the complexity of the simulations, analysis, and air traffic management capabilities across the airspace system ${ }^{(138,139)}$.

\subsection{Automatic navigation}

Automatic navigation is an intense area of research at present, and some of the major challenges are: sense and avoid (SAA), adaptive task assignment and path planning, fault tolerant control, and formation flight strategies.

UAVs are expected to be able to safely operate in all kinds of airspace conditions, this means detecting and avoiding collisions in cooperative (aircraft with communication equipment such as TCAS II or ADS-B) and non-cooperative scenarios (detection of other aircraft via LIDAR or EO sensors) through a variety of strategies. SAA technologies are the target of extensive research ${ }^{(140)}$.

Autonomous routing and task assignment solutions can be achieved through solving complex problems such as vehicle routing and traveling salesman problem ${ }^{(141)}$. Tabu search heuristics and receding horizon control techniques can account for 'pop-up' threats and moving targets, and have been successfully applied to combat simulations, although these strategies can be adopted for civil applications ${ }^{(142,143)}$.

Formation flight is highly dependent on SAA technologies. Several strategies have been proposed, such as the distance-error based algorithms for leader-follower scenarios ${ }^{(144,145)}$, multi-agent swarm formations ${ }^{(146)}$, and a completely different approach based on digital pheromones inspired on electrostatic and gravitational field dynamics $^{(147)}$, among many others. These strategies share the need for robust communications and reliable sensors.

Command, control and communication (C3) technologies are essential for unmanned operations in permissive and non-permissive airspace ${ }^{(148)}$. NATO STANAG 4586 aims to provide interoperability standards for UAV communications and bandwidth requirements ${ }^{(149)}$.

Increased autonomy levels in UAVs result in fundamental changes on the relationship between operator and machine. Permitted autonomy levels, information exchange requirements and human-machine interface requirements should form the base of the control philosophy behind UAV and UCAV operations. Pilot authorisation and control of tasks (PACT) levels show that areas such as planning and tactics offer great potential for co-operation between operator and machine, while health monitoring, and self-defence would strongly benefit from a highly autonomous system ${ }^{(150)}$. Increasing autonomy would also lead to reduced 
bandwidth and energy demands for communications, allowing the command of multiple vehicles by a single operator $^{(151)}$.

\subsection{ETHICAL CONCERNS}

\subsection{Surveillance}

The use of UAVs is now fairly widespread and current applications include public security, law enforcement, border patrol, emergency services, and civil and commercial uses, such as remote sensing for smart agricultural practices. It has been shown that current surveillance related legislation does not account for the variety of applications and technologies integrated into unmanned aircraft, as opposed to other surveillance equipment like CCTV and communications interceptions ${ }^{(152)}$. A risk perception study carried out in Australia identified privacy violations resulting from the use of unmanned vehicles as one of the main concerns held by the public ${ }^{(153)}$.

\subsection{UAVs in combat}

The main ethical concerns on the use of UAVs in combat and strike roles are:

1. UAVs encourage early use of force due to the lack of risk to human operators.

It has been argued that UAVs are not transformative in the sense that they offer no strictly unique capabilities when compared to manned combat aircraft ${ }^{(10)}$, and they have been proven to be extremely vulnerable to all kinds of enemy threats, which limits how early current UAVs can be used in conflict ${ }^{(154)}$.

2. The morality behind autonomous operations is unclear, especially when it comes to target identification and engagement.

Automatic target recognition (ATR) algorithms are currently under intense research focus due to the reported '[unacceptably high] false-alarm rate of both human and machine-based radar image recognition'(155). However, countries that operate UAVs in combat roles are committed to retaining human oversight over all weapon-release decisions' and to subject their crew to 'stringent rules of engagement that ensure lawfully used armed force. ${ }^{,(156, \text { p.2.9) }}$

3. UAV operators are detached from the reality of combat, usually called the 'video-game effect' or 'playstation effect'.

Due to sustained surveillance capabilities provided by UAVs, operators are able to observe the target area and evaluate its validity for longer periods of time without the physical and psychological strain of combat pilots, reducing decision errors. There is plenty of testimony from operators and military commanders emphasizing the realism of remote operations; for instance, Air Force Major S. Rogers says that "Physically, we may be in Vegas, but mentally, we're flying over Iraq. It feels real.",(157)

4. The policies behind drone strikes are not fully disclosed due to matters of national security, which could make them susceptible to abuse.

Signature strikes are characterised by targeting groups whose behaviour corresponds to that associated with terrorist activity, even when their identities are unknown. Intelligence data gathered exclusively through unmanned vehicles serving ISR roles can lead to misinterpretation of the suspects' behaviour. Even though this argument focuses on the policy and not on the vehicles themselves, designers and engineers can include a certain degree of ethics during the design process through advanced sensors, robust communications and a clear chain of responsibility ${ }^{(157)}$. Paradoxically, characteristics inherent to UAVs (sustained surveillance capabilities, advanced sensors, real time communication) that would enable them to comply with international humanitarian law seem to ease the infringement of these same laws. Although this is just a tentative statement, the argument is compelling when observed through cognitive consistency and misperception theories ${ }^{(158)}$. This is perhaps the most compelling argument against the use of unmanned aircraft in combat roles.

5. Lack of information on strike effectiveness makes it difficult for international humanitarian law agencies to monitor operations.

The real number of civilian casualties is hard to determine due to security reasons and dangers proper to the areas of conflict. Mainstream media seem to underreport the number of casualties when compared to data from the International Bureau of Journalism ${ }^{(159)}$. However, a case has been made by local (to the conflict zone) 
researchers against the 'inflated' number of reported civilian casualties and the negative opinion on drone strikes held by locals ${ }^{(160)}$. A database which compiles UAV strike data over Pakistan from 2004 to 2007 shows that UAVs result in 17 to 1 militant to civilian casualty ratio, compared to an alarming 0.125 to 1 militant to civilian ratio estimated in all other armed conflicts in the year $2000^{(161)}$.

Finally, a compelling argument in favour of the use of UAVs in combat is presented by introducing the principle of unnecessary risk, which demands that 'no more risk than is required for accomplishment of $G$ ( $G$ being a good or just goal) [...] is ordered by $X$ to be incurred by $Y$ '. From this, it follows that if the goal is good and justifiable the use of unmanned aircraft is not only necessary but morally obligatory ${ }^{(162)}$.

\subsection{CONCLUSIONS}

This paper has briefly summarised the historical background of unmanned vehicles in military uses and the reasons behind the evolution towards Unmanned Combat Aerial Vehicles. The main technology demonstrator programs currently under development were also discussed, and due to the nature of the projects, most of the detailed technical information is not publicly available. As it can be seen from the technological challenges section, UCAVs are highly constrained designs that require a high-level multidisciplinary integration from the earliest design stages in order to accurately match the operational requirements with their impacts on the configuration. The tendency of UCAV designs to be that of a delta wing, lambda wing or BWB is due to the tendency of stealth requirements to dominate.

The inclusion of good stealth characteristics in terms of RCS and IRS signatures impacts the aerodynamics, performance, packaging and system complexity of the configurations. Fast and accurate prediction tools of the complex aerodynamic and stability interactions for a wide range of operational speeds and attitudes are vital in UCAV designs. Aeroelastic considerations must be included during early design stages due to the interaction between the complex vortex flow topology and the structure of the aircraft. Composite materials offer significant weight saving advantages and the opportunity of aeroelastic tailoring; however, lightning strike protection and in-field reparability must be carefully analysed. Packaging constraints are of significant importance; employing good design practices, such as efficient geometric parametrisation can address some of these issues during the early conceptual design stages.

Multidisciplinary design analysis and optimisation frameworks are a common practice during the initial design studies for UCAVs. A variety of fidelity levels are used during early design studies, with common methods being empirical models, regression analysis, and low order numerical solvers such as vortex lattice or panel methods for aerodynamics and stability. The majority of conceptual design studies aim at developing subsonic configurations for strike missions, with cruise and dash speeds well into the transonic region. Payloads rarely surpass $2000 \mathrm{~kg}$ and are usually specified in particular weapon requirements. Some of the reported main constraints for UCAVs are the low maximum allowable incidence due to pitch-up phenomena encountered, which impacts field performance constraints and engine sizing, which results in heavier aircraft with a larger centre section for buried engines.

In terms of airworthiness and certification, several provisional standards and rules have been pushed forward by the main aeronautic authorities around the globe. The impact of unmanned aircraft on the airspace, as well as safety metrics, is being evaluated through large simulations and flight tests. This information will feed into the required policies and standards for unmanned operations in the civil airspace systems.

The increased levels of autonomy required for safe unmanned operations, both civil and military, are a huge challenge, some of the major research areas being detect and avoid, formation flight, automated task assignment, and flexible but robust command, control and communication architectures.

On the ethical aspect, the main public concern is the violation of privacy resulting from unmanned aircraft operations. The most relevant arguments against the use of UAVs in combat scenarios are the early use of force due to the lack of risk to human operators, the so-called 'video game effect', signature strike policies, and the lack of transparency on unmanned operations and their effectiveness. As it happens with any new technology, cooperative and multidisciplinary efforts between policy makers, defence authorities, industry, and international law organisations are the key to enabling UCAV operations while at the same time abiding by international humanitarian laws. 


\section{REFERENCES}

1. HaUlman D. U.S. Unmanned Aerial Vehicles in Combat, 1991-2003. Maxwell AirForce Base; June 2003. Available at: http://oai.dtic.mil/oai/oai?verb=getRecord\&metadataPrefix=html\&identifier=ADA434033

2. WyATT EC., HIRSCHBERG MJ. Transforming the Future Battlefield: The DARPA/Air Force Unmanned Combat Air Vehicle (UCAV) Program, AIAA 2003-2616. AIAA/ ICAS International Air and Space Symposium and Exposition. Dayton, Ohio 14-17 July Reston, VA: AIAA; 2003. Available at: DOI:10.2514/6.2003-2616

3. EHRHARD TP. Air Force UAVs: The Secret History. Arlington; July 2010. Available at: http://oai.dtic.mil/oai/oai?verb=getRecord\&metadataPrefix=html\&identifier=ADA525674

4. MERLIN PW. Design and Development of the Blackbird: Challenges and Lessons Learned, AIAA 20091522. 47th AIAA Aerospace Sciences Meeting. Orlando, Florida 5-8 January Reston, VA: AIAA; 2009. Available at: DOI:10.2514/6.2009-1522

5. HIRSCHBERG MJ. To Boldly Go Where No Unmanned Aircraft Has Gone Before: A Half-Century of DARPA's Contributions to Unmanned Aircraft, AIAA 2010-158. 48th AIAA Aerospace Sciences Meeting Including the New Horizons Forum and Aerospace Exposition. Orlando, Florida 4-7 January Reston, VA: AIAA; 2010. Available at: DOI:10.2514/6.2010-158

6. DIXON JR. UAV Employment in Kosovo: Lessons for the Operational Commander. Newport; February 2000.

7. COMMITTEE FOR THE REVIEW OF ONR's Uninhabited COMBAT AIR VEHICLES PROGRAM - NAVAL STUDIES BOARD. Review of ONR's Uninhabited Combat Air Vehicles Program. Washington DC: National Academies Press; 2000.

8. Newcome L. Unmanned Aviation : A Brief History Of Unmanned Aerial Vehicles. 1st ed. Reston, VA: AIAA; 2004.

9. Serle J., Fielding-Smith A. The Bureau of Investigative Journalism. Monthly Updates on the Covert War. 2015. Available at: https://www.thebureauinvestigates.com/2015/09/02/monthly-drone-reportaugust-2015-32-us-strikes-hit-afghanistan-alone/ (Accessed: 4 May 2016)

10. Davis LE., MCNerney MJ., ChOW J., Hamilton T., Harting S., Byman D. Armed and Dangerous? UAVs and U.S. Security. Rand Corporation Research Report Series. Santa Monica, California; 2014. Available at: http://www.rand.org/pubs/research_reports/RR449.html

11. HARRISON GJ. Unmanned Aircraft Systems (UAS): Manufacturing Trends. January 2013. Available at: http://www.fas.org/sgp/crs/natsec/R42938.pdf

12. MINISTRY OF DeFENCE. Joint Doctrine Note 2/11: The UK Approach To Unmanned Aircraft Systems. Swindon; March 2011. Available at: https://www.gov.uk/government/uploads/system/uploads/attachment_data/file/33711/20110505JDN_21 1_UAS_v2U.pdf

13. United States General Accounting OfFice. Matching Resources with Requirements Is Key to the Unmanned Combat Air Vehicle Program's Success, GAO-03-598. Washington D.C.; June 2003. Available at: www.gao.gov/cgi-bin/getrpt?GAO-03-598

14. WhitTEnbury J. Configuration Design Development of the Navy UCAS-D X-47B, AIAA 2011-7041. AIAA Centennial of Naval Aviation Forum ' 100 Years of Achievement and Progress'. Virginia Beach, Virginia 21-22 September Reston, VA: AIAA; 2011. Available at: DOI:10.2514/6.2011-7041

15. De NeVE A., WASINSKI C. Looking Beyond the J-UCAS's Demise. Defense \& Security Analysis. 2011; 27(3): 237-249. Available at: DOI:10.1080/14751798.2011.604484

16. WISE KA. First Flight of the X-45A Unmanned Combat Air Vehicle (UCAV), AIAA 2003-5320. AIAA Atmospheric Flight Mechanics Conference and Exhibit. Austin, Texas 11-14 August Reston, VA: AIAA; 2003. Available at: DOI:doi:10.2514/6.2003-5320 
17. MALENIC M. Debate over UCLASS capabilities increases programme risk, auditors warn. IHS Jane's Defence Weekly. Washington D.C.; May 2015; Available at:

http://www.janes.com/article/51133/debate?over?uclass?capabilities?increases?programme?risk?auditor s?warn

18. MALENIC M. USN demonstrates autonomous aerial refuelling with X-47B. IHS Jane's Defence Weekly. Washington D.C.; April 2015; Available at:

http://www.janes.com/article/50923/usn?demonstrates?autonomous?aerial?refuelling?with?x?47b

19. GERTLER J. History of the Navy UCLASS Program Requirements : In Brief. August 2015.

20. CAREY B. U.S. Navy Readies Requirements for Unmanned MQ-25 Stingray. AINonline. March 2016;

21. U.S. NAVY. Naval Air Systems Command - Aircraft and Weapons. MQ-25 UAS. Available at: http://www.navair.navy.mil/index.cfm?fuseaction=home.display\&key=A1DA3766-1A6D-4AEA-B462F91FE43181AF (Accessed: 6 April 2017)

22. NASA. Boeing's Phantom Ray Makes First Flight. 2011. Available at: http://www.nasa.gov/centers/dryden/Features/phantom_ray_first_flight.html\#.Vyx0DIQrJpg (Accessed: 6 May 2016)

23. DASSAUlt AviATION. NEURON. 2013. Available at: http://www.dassaultaviation.com/en/defense/neuron/introduction/ (Accessed: 2 February 2016)

24. LARRINAGA N DE., IHS L., WEEKLY D. Neuron completes Italian flight trials. IHS Jane's Defence Weekly. London; August 2015; Available at: http://www.janes.com/article/53814/neuron?completes?italian?flight?trials

25. BAE SYSTEMS. Taranis. 2016. Available at: http://www.baesystems.com/en/product/taranis (Accessed: 2 February 2016)

26. BEALE J. Top secret UK drone Taranis makes first flight. BBC News. February 2014; Available at: http://www.bbc.co.uk/news/uk?26046696

27. Morales A. UK and France to Unveil \$2 Billion Drone Project. Bloomberg. March 2016; Available at: http://www.bloomberg.com/news/articles/2016?03?03/u?k?france?2?billion?drone?project?to?benefit?b ae?dassault

28. PubBY M. Government set to clear Rs 3,000 core plan to develop engine for India's first UCAV. The Economic Times. 2015. Available at: http://economictimes.indiatimes.com/news/defence/governmentset-to-clear-rs-3000-crore-plan-to-develop-engine-for-indias-first-ucav/articleshow/49775096.cms (Accessed: 14 August 2016)

29. TRIMBLE S. ALMOST GREAT: Nine legendary (but cancelled) Russian aircraft. FlightGlobal. 2015. Available at: https://www.flightglobal.com/news/articles/almost-great-nine-legendary-but-cancelledrussian-415954/ (Accessed: 14 August 2016)

30. HsU B. China's 'Sharp Sword' UCAV is Spotted Taxiing. AINonline. May 2013; Available at: http://www.ainonline.com/aviation?news/defense/2013?05?17/chinas?sharp?sword?ucav?spotted?taxiin g

31. HitZEL SM., ZIMPER D. Model Scale and 'Real' Flight of Generic UCAV and Advanced Combat Aircraft - An Industrial Perspective, AIAA 2014-2267. 32nd AIAA Applied Aerodynamics Conference. Atlanta 16-20 June Reston, VA: AIAA; 2014. Available at: DOI:10.2514/6.2014-2267

32. TAHA HE., HAJJ MR. Effects of the Stealth Requirements on the Aerodynamic Performance of the X47B, AIAA 2013-1674. 54th AIAA/ASME/ASCE/AHS/ASC Structures, Structural Dynamics, and Materials Conference. Boston, Massachusetts 8-11 April Reston, VA: AIAA; 2013. Available at: DOI:10.2514/6.2013-1674

33. BRown A. The Effect of Signature Constraints on the F-117 Configuration Development, AIAA 20035761. AIAA Guidance, Navigation, and Control Conference and Exhibit. Austin, Texas 11-14 August 
34. ManavoĞLu B., YAZgan E. Tracking of Real Airborne Targets with Multistatic Passive Radars in 3D. Proceedings of the 15th International Radar Symposium. Gdansk, Poland 16-18 June IEEE; 2014. Available at: DOI:10.1109/IRS.2014.6869281

35. Aviation Week Network. S-300 Surface-To-Air Missile System. Aerospace Daily \& Defense Report. August 2015; : 6-10.

36. Borkar VG., GHOSh A., Singh RK., ChOurasia N. Radar Cross-Section Measurement Techniques. Defence Science Journal. 2010; 60(2): 204-212. Available at: DOI:10.14429/dsj.60.341

37. Aerospace MD. A Review of High-Frequency Radar Cross Section Analysis Capabilities at McDonnell Douglas Aerospace. IEEE Antennas and Propagation Magazine. 1995; 37(5): 33-43.

38. Liangliang C., Kuizhi Y., CuiFang X., Dazhao Y. RCS Numerical Simulation of Stealth Modified Three-Surface Aircraft. International Journal of Aeronautical and Space Sciences. 2016; 17(1): 101108. Available at: DOI:10.5139/IJASS.2016.17.1.101

39. MATHWORKS. POFACETS4.1. 2012. Available at: http://www.mathworks.com/matlabcentral/fileexchange/35861-pofacets4-1 (Accessed: 17 March 2016)

40. LeE DS., GonZalez LF., Srinivas K., Auld DJ., Wong KC. Aerodynamic/RCS Shape Optimisation of Unmanned Aerial Vehicles using Hierarchical Asynchronous Parallel Evolutionary Algorithms, AIAA 2006-3331. 24th Applied Aerodynamics Conference. San Francisco, California 5-8 June Reston, VA: AIAA; 2006. Available at: DOI:10.5019/j.ijcir.2007.106

41. UfIMTSEV PY. Comments on Diffraction Principles and Limitations of RCS Reduction Techniques. Proceedings of the IEEE. 1996; 84(12): 1830-1851. Available at: DOI:10.1109/5.546440

42. JOHANSSON M. Propulsion Integration in an UAV, AIAA 2006-2834. 24th Applied Aerodynamics Conference. San Francisco, California 5-8 June Reston, VA: AIAA; 2006. Available at: DOI:doi:10.2514/6.2006-2834

43. SHI L., GUO RW. Serpentine Inlet Design and Analysis, AIAA 2012-0839. 50th AIAA Aerospace Sciences Meeting including the New Horizons Forum and Aerospace Exposition. Nashville, Tennessee 9-12 January Reston, VA: AIAA; 2012. Available at: DOI:10.2514/6.2012-839

44. Zhang J-M., WANG C-F., Lum K-Y. Multidisciplinary Design of S-shaped Intake, AIAA 2008-7060. 26th AIAA Applied Aerodynamics Conference. Honolulu, Hawaii 18-21 August Reston, VA: AIAA; 2008. Available at: DOI:10.2514/6.2008-7060

45. BANKs HT., Ito K., KePler GM., ToIVANEN JA. Material Surface Design to Counter Electromagnetic Interrogation of Targets. SIAM Journal on Applied Mathematics. 2006; 66(3): 1027-1049. Available at: DOI: $10.1137 / 040621430$

46. Xu W., He Y., Kong P., Li J., Xu H., Miao L., ET Al. An Ultra-Thin Broadband Active Frequency Selective Surface Absorber for Ultrahigh-Frequency Applications. Journal of Applied Physics. 2015; 118(18). Available at: DOI:10.1063/1.4934683

47. Tennant A., Chambers B. Adaptive Radar Absorbing Structure with PIN Diode Controlled Active Frequency Selective Surface. Smart Materials and Structures. 2004; 13: 122-125. Available at: DOI:10.1088/0964-1726/13/1/013

48. ОH JH., ОH KS., KIM CG., Hong CS. Design of Radar Absorbing Structures Using Glass/Epoxy Composite Containing Carbon Black in X-Band Frequency Ranges. Composites Part B: Engineering. 2004; 35(1): 49-56. Available at: DOI:10.1016/j.compositesb.2003.08.011

49. CHIN WS., LEE DG. Development of the Composite RAS (Radar Absorbing Structure) for the X-Band Frequency Range. Composite Structures. 2007; 77(4): 457-465. Available at: DOI:10.1016/j.compstruct.2005.07.021 
50. NENG-Jing L., YI-TING Z. A Survey of Radar ECM and ECCM. IEEE Transactions on Aerospace and Electronic Systems. 1995; 31(3): 1110-1120. Available at: DOI:10.1109/7.395232

51. Kim J., Hespanha P. Cooperative Radar Jamming for Groups of Unmanned Air Vehicles. Proceedings of the IEEE Conference on Decision and Control. 2004; 1: 632-637. Available at: DOI:10.1109/CDC.2004.1428715

52. NGuYen D., SAhin C., Shishkin B., KAndasAmy N., DandeKar KR. A Real-Time and ProtocolAware Reactive Jamming Framework Built on Software-Defined Radios. Proceedings of the 2014 ACM workshop on Software radio implementation forum - SRIF '14. 2014; (August): 15-22. Available at: DOI:10.1145/2627788.2627798

53. Lichtman M., ReED JH. Analysis of Reactive Jamming Against Satellite Communications. International Journal of Satellite Communications and Networking. 2016; 34: 195-210. Available at: DOI:10.1002/sat.1111

54. GUSTAFSSON K. Implementation of a Digital Radio Frequency Memory in a Xilinx Virtex-4 FPGA. Linköpings University; 2005.

55. Sheng X., Yuanming X. Simulation Analysis of an Active Cancellation Stealth System. Optik. Elsevier GmbH.; 2014; 125(18): 5273-5277. Available at: DOI:10.1016/j.ijleo.2014.05.016

56. Mahulikar SP., Sonawane HR., ARVInd RaO G. Infrared Signature Studies of Aerospace Vehicles. Progress in Aerospace Sciences. 2007; 43(7-8): 218-245. Available at:

DOI:10.1016/j.paerosci.2007.06.002

57. RaO GA., MahUliKar SP. New Criterion for Aircraft Susceptibility to Infrared Guided Missiles. Aerospace Science and Technology. 2005; 9(8): 701-712. Available at: DOI:10.1016/j.ast.2005.07.005

58. IANNARILLI FJ., WOHLERS MR. End-to-End Scenario-Generation Model for IRST Performance Analysis. SPIE Signal and Data Processing of Small Targets. 1991; 1481: 187-197.

59. NoAh M., Krlstl J., Schroeder J., Corporation O., SANDlORd BP. NIRATAM - NATO Infrared Air Target Model. SPIE Surveillance Technologies. 1991; 1479: 275-282.

60. Johansson M., Dalenbring M. SIGGE, a Prediction Tool for Aeronautical IR Signatures, and its Applications, AIAA 2006-3276. 9th AIAA/ASME Joint Thermophysics and Heat Transfer Conference. San Francisco, California 5-8 June Reston, VA: AIAA; 2006. Available at: DOI:10.2514/6.2006-3276

61. An CH., KAng DW., BaEK ST., MyOng RS., Kim WC., ChOI SM. Analysis of Plume Infrared Signatures of S-Shaped Nozzle Configurations of Aerial Vehicle. Journal of Aircraft. 2016; 53(6): 1768-1778. Available at: DOI:10.2514/1.C033685

62. CZARNECKI GJ. US 6267039 B1: Aircraft missile-hit survivability using infrared lamp and sacrificial support structure. United States of America; 2001. Available at: https://www.google.ch/patents/US6267039

63. SIOURIS S., QIN N. Study of the effects of wing sweep on the aerodynamic performance of a blended wing body aircraft. Proc. IMechE Part G: Journal of Aerospace Engineering. 2007; 221(October 2015): 47-55. Available at: DOI:10.1243/09544100JAERO93

64. VOS R., FAROKHI S. Introduction to Transonic Aerodynamics. Springer Science+Business Media; 2015.

65. Chester Furlon G., MCHugh JG. A summary and analysis of the low-speed longitudinal characteristics of swept wings at high Reynolds number. - NACA Report 1339. 1952.

66. GURSUL I. Review of Unsteady Vortex Flows over Slender Delta Wings. Journal of Aircraft. 2005; 42(2): 299-319. Available at: DOI:10.2514/1.5269

67. DeLERY JM. Aspects of Vortex Breakdown. Progress in Aerospace Sciences. 1994; 30: 1-59. Available at: DOI:10.1016/0376-0421(94)90002-7

68. Gursul I., Gordnier R., Visbal M. Unsteady Aerodynamics of Nonslender Delta Wings. Progress in 
Aerospace Sciences. 2005; 41(7): 515-557. Available at: DOI:10.1016/j.paerosci.2005.09.002

69. GuRSUl I. Vortex Flows on UAVs: Issues and Challenges. Aeronautical Journal. 2004; 108(1090): 597-610. Available at: DOI:10.1017/S0001924000000439

70. NATO SCIENCE AND TECHNOLOGY ORGANIZATION. RTO-TR-AVT-080 - Vortex Breakdown over Slender Delta Wings. Brussels; October 2009.

71. NATO SCIENCE AND TEChNOLOGY ORGANIZATION. RTO-TR-AVT-113 - Understanding and Modeling Vortical Flows to Improve the Technology Readiness Level for Military Aircraft. Brussels; October 2009.

72. GHOREYShi M., RYSZKA K., CUMmings RM., LOFTHOUSE AJ. Vortical Flow Prediction of the AVT-183 Diamond Wing, AIAA 2015-0292. 53rd AIAA Aerospace Sciences Meeting. Kissimmee, Florida 5-9 January Reston, VA: AIAA; 2015. Available at: DOI:doi:10.2514/6.2015-0292

73. Cummings RM., Schutte A., HÜBner A. Overview of Stability and Control Estimation Methods from NATO STO Task Group AVT-201, AIAA 2013-0968. 51st AIAA Aerospace Sciences Meeting including the New Horizons Forum and Aerospace Exposition. Grapevine, Texas 7-10 January Reston, VA: AIAA; 2013. Available at: DOI:10.2514/6.2013-968

74. SchütTE A., Hummel D., Hitzel SM. Flow Physics Analyses of a Generic Unmanned Combat Aerial Vehicle Configuration. Journal of Aircraft. 2012; 49(6): 1638-1651. Available at: DOI:10.2514/1.C031386

75. Lofthouse AJ., Ghoreyshi M., Cummings RM. Static and Dynamic Simulations of a Generic UCAV Geometry Using the Kestrel Flow Solver. 32nd AIAA Applied Aerodynamics Conference AIAA. Atlanta 16-20 June Reston, Virginia: AIAA; 2014. Available at: DOI:10.2514/6.2014-2264

76. OL M V. Water Tunnel Velocimetry Results for the 1303 UCAV Configuration, AIAA 2006-2990. 24th Applied Aerodynamics Conference. San Francisco, California 5-8 June Reston, VA: AIAA; 2006. Available at: DOI:doi:10.2514/6.2006-2990

77. Cummings RM., Morton SA., Siegel SG. Numerical Prediction and Wind Tunnel Experiment for a Pitching Unmanned Combat Air Vehicle. Aerospace Science and Technology. 2008; 12(5): 355-364. Available at: DOI:10.1016/j.ast.2007.08.007

78. MCPARlin SC., BruCE RJ., HePwOrth AG., RAE AJ. Low Speed Wind Tunnel Tests on the 1303 UCAV Concept, AIAA 2006-2985. 24th Applied Aerodynamics Conference. San Francisco, California 5-8 June Reston, VA: AIAA; 2006.

79. SHIM HJ., PARK SO. Low-speed Wind-tunnel Test Results of a BWB-UCAV Model. Procedia Engineering. Elsevier B.V.; 2013; 67: 50-58. Available at: DOI:10.1016/j.proeng.2013.12.004

80. LIERSCH CM., HUBER KC. Conceptual Design and Aerodynamic Analyses of a Generic UCAV Configuration, AIAA 2014-2001. 32nd AIAA Applied Aerodynamics Conference. Atlanta 16-20 June Reston, VA: AIAA; 2014. Available at: DOI:10.2514/6.2014-2001

81. TOMAC M., RizZi A., NAngia RK., MEndenhall MR., Perkins SC. Engineering Methods on the SACCON Configuration - Some Design Considerations, AIAA 2010-4398. 28th AIAA Applied Aerodynamics Conference. Chicago, Illinois 28 June - 1 July Reston, VA; 2010. Available at: DOI:doi:10.2514/6.2010-4398

82. Woolvin SJ. A Conceptual Design Study of the 1303 UCAV Configuration, AIAA 2006-2991. 24th Applied Aerodynamics Conference. San Francisco, California 5-8 June Reston, VA: AIAA; 2006.

83. Huber KC., Vicroy DD., SchutTe A., Hubner A-R. UCAV Model Design and Static Experimental Investigations to Estimate Control Device Effectiveness and Stability and Control Capabilities, AIAA 2014-2002. 32nd AIAA Applied Aerodynamics Conference. Atlanta 16-20 June Reston, VA: AIAA; 2014. Available at: DOI:10.2514/6.2014-2002

84. Stenfelt G., Ringertz U. Lateral Stability and Control of a Tailless Aircraft Configuration. Journal of 
Aircraft. 2009; 46(6): 2161-2163. Available at: DOI:10.2514/1.41092

85. Chung J., Hallberg E., Cox S., Plyler M. Landing Pitch Control Analysis for a Blended Wing Body UCAV, AIAA 2010-1035. 48th AIAA Aerospace Sciences Meeting Including the New Horizons Forum and Aerospace Exposition. Orlando, Florida 4-7 January Reston, VA: AIAA; 2010. Available at: DOI:10.2514/6.2010-1035

86. PARK J., Jo Y., Y I S., CHOI J-Y., RAJ P., CHOI S. Variable-Fidelity Multidisciplinary Design Optimization for Innovative Control Surface of Tailless Aircraft, AIAA 2016-4038. 34th AIAA Applied Aerodynamics Conference. Washington D.C. 13-17 June Reston, VA: AIAA; 2016. Available at: DOI:10.2514/6.2016-4038

87. WILLIAMS DR., SEIDEL J. Crossed-Actuation AFC for Lateral-Directional Control of an ICE-101/Saccon UCAV, AIAA 2016-3167. 8th AIAA Flow Control Conference. Washington D.C. 13-17 June Reston, VA: AIAA; 2016. Available at: DOI:10.2514/6.2016-3167

88. ZIMPER D., REIN M. Experimental and Numerical Analysis of the Transonic Vortical Flow Over a Generic Lambda Wing Configuration, AIAA 2014-2005. 32nd AIAA Applied Aerodynamics Conference AIAA. Atlanta 16-20 June Reston, VA: AIAA; 2014. Available at: DOI:10.2514/6.20142005

89. FOAM MATRIX INC. Foam Matrix. Our Technology. 2016. Available at: http://www.foammatrix.com/tech (Accessed: 12 September 2016)

90. GKN AEROSPACE. GKN produces components for X-47B Navy. Reinforced Plastics. February 2006;

91. McConnell VP. Resins for the Hot Zone, Part I: Polyimides. Composites World. July 2009; 17(4).

92. MCConnell VP. Resins for the Hot Zone, Part II: BMIs, CEs, Benzoxazines and Phthalonitriles. Composites World. September 2009; 17(5).

93. Di SANTE R. Fibre Optic Sensors for Structural Health Monitoring of Aircraft Composite Structures: Recent Advances and Applications. Sensors. 2015; 15(8): 18666-18713. Available at: DOI:10.3390/s150818666

94. Gagné M., Therriault D. Lightning strike protection of composites. Progress in Aerospace Sciences. Elsevier; 2014; 64: 1-16. Available at: DOI:10.1016/j.paerosci.2013.07.002

95. Kutlu Z., Chang F-K. Modeling Compression Failure of laminated Composites Containing Multiple Through-the-Width Delaminations. Journal of Composite Materials. 1992; 26(3): 350-387. Available at: DOI:10.1177/002199839202600303

96. Riccio A., RAIMONDO A., SCARAMUZZINO F. A robust numerical approach for the simulation of skinstringer debonding growth in stiffened composite panels under compression. Composites Part B: Engineering. Elsevier Ltd; 2015; 71: 131-142. Available at: DOI:10.1016/j.compositesb.2014.11.007

97. RicCiO A., De LuCA A., Di Felice G., CAPUTO F. Modelling the simulation of impact induced damage onset and evolution in composites. Composites Part B: Engineering. Elsevier Ltd; 2014; 66: 340-347. Available at: DOI:10.1016/j.compositesb.2014.05.024

98. PERUGini P., RicCIO A., SCARAMUZZINO F. Influence of Delamination Growth and Contact Phenomena on the Compressive Behaviour of Composite Panels. Journal of Composite Materials. 1999; 33(15): $1433-1456$.

99. MYHRE SH., LABOR JD. Repair of advanced composite structures. Journal of Aircraft. 1981; 18(7): 546-552. Available at: DOI:10.2514/6.1980-776

100. TZETZIS D., HogG PJ. Infield composites repair techniques for combat aircraft: research and development perspective. Materials Technology. 2007; 22(1): 2-9. Available at: DOI:10.1179/175355507X196475

101. GRAY J., GURSUl I., ButLer R. Aeroelastic Response of a Flexible Delta Wing due to Unsteady Vortex 
Flows, AIAA 2003-1106. 41st Aerospace Sciences Meeting and Exhibit. Reno, Nevada 6-9 January Reston, VA: AIAA; 2003. Available at: DOI:10.2514/6.2003-1106

102. AtTAR P., GORDNIER R., VisBal M. Numerical Simulation of the Buffet of a Full Span Delta Wing at High Angle of Attack, AIAA 2006-2075. 47th AIAA/ASME/ASCE/AHS/ASC Structures, Structural Dynamics, and Materials Conference. Newport, Rhode Island 1-4 May Reston, VA: AIAA; 2006. Available at: DOI:10.2514/6.2006-2075

103. Voß A., KlimmeK T. Design and Sizing of a Parametric Structural Model for a UCAV Configuration for Loads and Aeroelastic Analysis. Deutscher Luft- und Raumfahrtkongress Göttingen, Germany: DLR German Aerospace Center, Institute of Aeroelasticity; 2015.

104. Voss G., CumnuantiP S., Neumann J. A Steady Aeroelastic Analysis of an Unmanned Combat Aircraft Vehicle Conceptual Design, AIAA 2011-3020. 29th AIAA Applied Aerodynamics Conference. Honolulu, Hawaii 27-30 June Reston, VA: AIAA; 2011. Available at: DOI:10.2514/6.2011-3020

105. Voss A., KLIMMEK T. Maneuver Loads Calculation with Enhanced Aerodynamics for a UCAV Configuration, AIAA 2016-3838. AIAA Modeling and Simulation Technologies Conference. Washington D.C. 13-17 June Reston, VA: AIAA; 2016. Available at: DOI:10.2514/6.2016-3838

106. Chapman RE. Unmanned Combat Aerial Vehicles: Dawn of a New Age? Air and Space Power Journal. 2002; 16(2): 60-73.

107. Levy A., Katz M., Katzuni O., Konevsky A., Frumkin J., Buium T., ET Al. Final Report Project 7-8: Team Cerberus - UCAV. Haifa, Israel; 2009.

108. AERospaCeWEB. Team Decepticon Storm Shadow. 2001. Available at: http://www.aerospaceweb.org/design/ucav/main.shtml (Accessed: 11 May 2016)

109. Pocock C. Study Contracts for Anglo--French UCAV Signed. AINonline. August 2012; Available at: http://www.ainonline.com/aviation-news/defense/2012-08-03/study-contracts-anglo-french-ucav-signed

110. Chaplin R., BIRCH T. The Aero-Acoustic Environment Within the Weapons Bay of A Generic UCAV, AIAA 2012-3338. 30th AIAA Applied Aerodynamics Conference. New Orleans, Louisiana 25-28 June Reston, VA: AIAA; 2012. Available at: DOI:10.2514/6.2012-3338

111. KULFAN BM. Universal Parametric Geometry Representation Method. Journal of Aircraft. 2008; 45(1): 142-158. Available at: DOI:10.2514/1.29958

112. Morris C., Allison D., Schetz J., KAPAnia R. Parametric Geometry Model for Multidisciplinary Design Optimization of Tailless Supersonic Aircraft. Journal of Aircraft. 2014; 51(5): 1455-1466. Available at: DOI:doi:10.2514/6.2012-4850

113. OKOnKwo P., SMith H. Packaging in a Multivariate Conceptual Design Synthesis of a BWB Aircraft. International Journal of Mechanical, Aerospace, Industrial, Mechatronic and Manufacturing Engineering. 2014; 8(6): 1063-1072.

114. StraAthof MH., Van ToOren MJL., VoskuiJl M., Vos R. Development and Implementation of a Novel Parametrization Technique for Multidisciplinary Design Initialization, AIAA 2010-3004. 51st AIAA/ASME/ASCE/AHS/ASC Structures, Structural Dynamics, and Materials Conference. Orlando, Florida 12-15 April Reston, VA: AIAA; 2010. Available at: DOI:10.2514/6.2010-3004

115. Woolvin SJ. UCAV Configuration \& Performance Trade-Offs, AIAA 2006-1264. 44th AIAA Aerospace Sciences Meeting and Exhibit. Reno, Nevada 9-12 January Reston, VA: AIAA; 2006.

116. JEON K., LEE J., BYUN Y., YU YH. Multidisciplinary UCAV System Design and Optimization Using Repetitive Response Surface Enhancement Technique, AIAA 2007-1972. 48th

AIAA/ASME/ASCE/AHS/ASC Structures, Structural Dynamics, and Materials Conference Honolulu, Hawaii: AIAA; 2007. Available at: DOI:10.2514/6.2007-1902

117. SAthe A., PAnT RS. Conceptual Design Studies of an Unmanned Combat Aerial Vehicle, AIAA 20109306. 10th AIAA Aviation Technology, Integration, and Operations (ATIO) Conference. Fort Worth, 
Texas 13-15 September Reston, VA: AIAA; 2010. Available at: DOI:10.2514/6.2010-9306

118. NGUYEn N-V., CHOI S-M., KIM W-S., JEON K-S., LEE J-W., BYUN Y-H. Multidisciplinary UCAV Design Using Variable Complexity Modeling, AIAA 2009-7093. 9th AIAA Aviation Technology, Integration, and Operations Conference (ATIO). Hilton Head, South Carolina 21-23 September Reston, VA: AIAA; 2009.

119. NGUYEn N-V., TyAn M., ChOI S-M., LeE J-W., KIM S., BYUn Y-H. Multidisciplinary Regional Jet Aircraft Design Optimization Using Advanced Variable Complexity Techniques, AIAA 2010-9192. 13th AIAA/ISSMO Multidisciplinary Analysis Optimization Conference. Fort Worth, Texas 13-15 September Reston, VA: AIAA; 2010. Available at: DOI:10.2514/6.2010-9192

120. NGUYen N-V., CHOI S-M., KIM W-S., LEE J-W., KIM S., NeUfELD D., ET AL. Multidisciplinary Unmanned Combat Air Vehicle system design using Multi-Fidelity Model. Aerospace Science and Technology. Elsevier Masson SAS; 2013; 26(1): 200-210. Available at: DOI:10.1016/j.ast.2012.04.004

121. GANGlin W. Key Parameters and Conceptual Configuration of Unmanned Combat Aerial Vehicle Concept. Chinese Journal of Aeronautics. Chinese Journal of Aeronautics; 2009; 22(4): 393-400. Available at: DOI:10.1016/S1000-9361(08)60116-8

122. ANDERSON RP. UCAV Backwards Engine Configuration. Advances in Aviation Safety Conference and Exposition. Daytona Beach, Florida. April 13-15 Warrendale, PA: SAE International; 1999.

123. MAVRIS DN., SOBAN DS., LARGENT MC. An application of a technology impact forecasting (TIF) method to an uninhabited combat aerial vehicle. 1999 World Aviation Conference. October 19-21. San Francisco, CA Warrendale, PA: SAE International; 1999. Available at: DOI:doi:10.2514/6.1999-5633

124. AHN J., LEE S., KIM J. A Robust Approach to Pre-Concept Design of UCAV Considering Survivability, AIAA 2002-5605. 9th AIAA/ISSMO Symposium on Multidisciplinary Analysis and Optimization Atlanta: AIAA; 2002.

125. LeE DS., GonZalez LF., SRinivas K., PERIAUX J. Robust Evolutionary Algorithms for UAV/UCAV Aerodynamic and RCS Design Optimisation. Computers and Fluids. 2008; 37(5): 547-564. Available at: DOI:10.1016/j.compfluid.2007.07.008

126. FAA. Integration of Civil Unmanned Aircraft Systems (UAS) in the National Airspace System (NAS) Roadmap. 2013. Available at: http://www.faa.gov/about/initiatives/uas/media/UAS_Roadmap_2013.pdf

127. Dalamagkidis K., Valavanis KP., Piegl LA. On Unmanned Aircraft Systems Issues, Challenges and Operational Restrictions Preventing Integration into the National Airspace System. Progress in Aerospace Sciences. 2008; 44(7-8): 503-519. Available at: DOI:10.1016/j.paerosci.2008.08.001

128. Federal Aviation Administration. Aircraft Certification. Special Airworthiness Certificate. 2015. Available at: https://www.faa.gov/aircraft/air_cert/airworthiness_certification/sp_awcert/ (Accessed: 16 May 2016)

129. Federal AVIATION Administration. Order 8130.34C. 2013.

130. U.S. DePARTMENT OF TRAnSPORTATION. Federal Aviation Administration. Certificates of Waiver or Authorization (COA). 2016. Available at:

https://www.faa.gov/about/office_org/headquarters_offices/ato/service_units/systemops/aaim/organizati ons/uas/Coa/ (Accessed: 12 October 2016)

131. ASTRAEA. ASTRAEA. 2015. Available at: http://astraea.aero/ (Accessed: 22 June 2016)

132. The European Parliament And the Council. Regulation (EC) No 216/2008 of the European Parliament and of the Council. Official Journal of the European Union. 2008.

133. NATO StANDARDIZATION AGENCY. STANAG 4671 - Unmammed Aerial Vehicle Systems Airworthiness Requirements (USAR). Brussels; September 2009.

134. ChINA DAILY INFORMATION Co. CHINADAILY Europe. Blue-sky thinking colors China's drone 
industry. 2014. Available at: http://europe.chinadaily.com.cn/business/201408/18/content_18436980.htm (Accessed: 15 October 2016)

135. Johnson M., Mueller ER., SAntiago C. Characteristics of a Well Clear Definition and Alerting Criteria for Encounters between UAS and Manned Aircraft in Class E Airspace. 11th USA/Europe Air Traffic Management Research and Development Seminar (ATM2015). 2015;

136. MurPhy JR., Williams-HAYES PS., Kim SK., BRIDges W., MARSTON M. Flight Test Overview for UAS Integration in the NAS Project, AIAA 2016-1756. AIAA Atmospheric Flight Mechanics Conference. San Diego, California 4-8 January Reston, VA: AIAA; 2016. Available at: DOI: $10.2514 / 6.2016-1756$

137. Jenie YI., VAN KAMPEN E-J., Ellerbroek J., HoEKSTRA JM. Safety Assessment of Unmanned Aerial Vehicle Operations in an Integrated Airspace, AIAA 2016-1000. AIAA Infotech @ Aerospace. San Diego, California 4-8 January Reston, VA: AIAA; 2016. Available at: DOI:10.2514/6.2016-1000

138. Prevot T., Rios J., Kopardekar P., Robinson III JE., Johnson M., Jung J. UAS Traffic Management (UTM) Concept of Operations to Safely Enable Low Altitude Flight Operations. 16th AIAA Aviation Technology, Integration, and Operations Conference. Washington D.C. 13-17 June Reston, VA: AIAA; 2016. Available at: DOI:10.2514/6.2016-3292

139. Prevot T., Homola J., Mercer J. From Rural to Urban Environments: Human/Systems Simulation Research for Low Altitude UAS Traffic Management (UTM). 16th AIAA Aviation Technology, Integration, and Operations Conference. Washington D.C. 13-17 June Reston, VA: AIAA; 2016. Available at: DOI:10.2514/6.2016-3291

140. YU X., ZHAng Y. Sense and Avoid Technologies with Applications to Unmanned Aircraft Systems: Review and Prospects. Progress in Aerospace Sciences. Elsevier; 2015; 74: 152-166. Available at: DOI:10.1016/j.paerosci.2015.01.001

141. Harder R., Hill R., MoOre J. A Java Universal Vehicle Router for Routing Unmanned Aerial Vehicles. International Transactions in Operational Research. 2004; 11(3): 259-275.

142. ShetTy VK., Sudit M., NAgi R. Priority-Based Assignment and Routing of a Fleet of Unmanned Combat Aerial Vehicles. Computers and Operations Research. 2008; 35(6): 1813-1828. Available at: DOI:10.1016/j.cor.2006.09.013

143. Zhang Y., Chen J., SHEn L. Real-Time Trajectory Planning for UCAV Air-to-Surface Attack Using Inverse Dynamics Optimization Method and Receding Horizon Control. Chinese Journal of Aeronautics. Chinese Society of Aeronautics and Astronautics; 2013; 26(4): 1038-1056. Available at: DOI:10.1016/j.cja.2013.04.040

144. BoskoviC JD., MeHRA RK., Li S-M. Semi-Globally Stable Formation Flight Control Design in Three Dimensions. Proceedings of the 40th IEEE Conference on Decision and Control (Cat. No.01CH37228) Orlando: IEEE; 2001. pp. 1059-1064. Available at: DOI:10.1109/.2001.981025

145. KAng S-M., PARK M-C., LEE B-H., Ahn H-S., GrAPH A. Distance-Based Formation Control with a Single Moving Leader. 2014 American Control Conference. Portland, Oregon 4-6 June AACC; 2014.

146. ZHU X., LIU Z., YANG J. Model of Collaborative UAV Swarm Toward Coordination and Control Mechanisms Study. Procedia Computer Science. 2015; 51: 493-502. Available at: DOI:10.1016/j.procs.2015.05.274

147. Parunak H Van., Purcell M., O’Connell R. Digital Pheromones for Autonomous Coordination of Swarming UAV's, AIAA 2002-3446. 1st Technical Conference and Workshop on Unmanned Aerospace Vehicles. Portsmouth, Virginia 20-23 May Reston, VA: AIAA; 2002. Available at: DOI:10.2514/6.2002-3446

148. STANSBURY RS., VyAS MA., WILSON TA. A technology survey and regulatory gap analysis of UAS technologies for C3. IEEE Aerospace Conference Proceedings. Big Sky, Massachusetts 7-14 March. 2009; Available at: DOI:10.1109/AERO.2009.4839604 
149. NATO StANDARDiZATION AgENCY. STANAG 4586 - Standard Interfaces of UAV Control System (UCS) for NATO UAV Interoperability. STANAG 4586 (Edition 3). Brussels; November 2012.

150. WhITE AD. The Human-Machine Partnership in UCAV Operations. The Aeronautical Journal. 2003; (February): 111-116. Available at: DOI:10.1017/S0001924000013786

151. Cummings M., Bruni S., Mercier S., Mitchell P. Automation architecture for single operator, multiple UAV command and control. The International C2 Journal. 2007; 1(2): 1-24. Available at: DOI:10.1017/CBO9781107415324.004

152. FInN RL., Wright D. Unmanned Aircraft Systems: Surveillance, Ethics and Privacy in Civil Applications. Computer Law and Security Review. Elsevier Ltd; 2012; 28(2): 184-194. Available at: DOI:10.1016/j.clsr.2012.01.005

153. Clothier RA., Greer DA., Greer DG., Mehta AM. Risk Perception and the Public Acceptance of Drones. Risk Analysis. 2015; 35(6): 1167-1183. Available at: DOI:10.1111/risa.12330

154. HAIDER A. Remotely Piloted Aircraft Systems in Contested Environments: A Vulnerability Analysis. Kalkar, Germany; September 2014.

155. US DoD. Defense Advanced Research Projects Agency. Target Recognition and Adaption in Contested Environments (TRACE). 2016. Available at: http://www.darpa.mil/program/trace (Accessed: 22 June 2016)

156. Ministry OF Defence. Joint Doctrine Publication 0-30. UK Air and Space Doctrine. Swindon; July 2013. Available at:

https://www.gov.uk/government/uploads/system/uploads/attachment_data/file/223495/jdp_0_30_uk_air _and_space_doctrine.pdf

157. SpARrow R. Killer Robots: Ethical Issues in the Design of Unmanned Systems for Military Applications. Science and Engineering Ethics. 2009; 15(2): 169-187.

158. Martin C. A Means-Methods Paradox and the Legality of Drone Strikes in Armed Conflict. The International Journal of Human Rights. 2015; 19(2): 142-175. Available at: DOI:10.1080/13642987.2014.998864

159. BaCHMAn J. The New York Times and The Washington Post. Journalism Studies. 2015; Available at: DOI:10.1080/1461670X.2015.1073118

160. TAJ F. The Year of the Drone Misinformation. Small Wars \& Insurgencies. 2010; 21(3): 529-535. Available at: DOI:10.1080/09592318.2010.505486

161. PlaW A. Sudden Justice. 7th Anual Conference on War and Peace. Prague. 1 May Prague; 2010.

162. STRAWSER BJ. Moral Predators: The Duty to Employ Uninhabited Aerial Vehicles. Journal of Miliatry Ethics. 2010; 9(4). Available at: DOI:10.1007/978-90-481-9707-1 
2017-06-23

\section{Technology challenges of stealth unmanned combat aerial vehicles}

Sepulveda Palacios, Eduardo

Cambridge University Press

Sepulveda E, Smith H. (2017) Technology challenges of stealth unmanned combat aerial vehicles. Aeronautical Journal, Volume 121, Issue 1243, September 2017, pp. 1261-1295

https://doi.org/10.1017/aer.2017.53

Downloaded from Cranfield Library Services E-Repository 